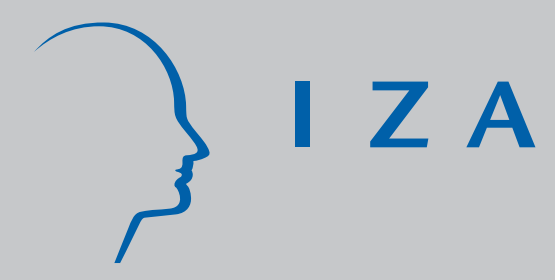

IZA DP No. 4028

Regulation and UK Retailing Productivity:

Evidence from Micro Data

J onathan Haskel

Raffaella Sadun

February 2009 


\title{
Regulation and UK Retailing Productivity: Evidence from Micro Data
}

\author{
Jonathan Haskel \\ Imperial College Business School, \\ CEPR, CeRIBA and IZA \\ Raffaella Sadun \\ London School of Economics, \\ AIM and CeRiBA \\ Discussion Paper No. 4028
February 2009
}

IZA

P.O. Box 7240

53072 Bonn

Germany

Phone: +49-228-3894-0

Fax: +49-228-3894-180

E-mail: iza@iza.org

Any opinions expressed here are those of the author(s) and not those of IZA. Research published in this series may include views on policy, but the institute itself takes no institutional policy positions.

The Institute for the Study of Labor (IZA) in Bonn is a local and virtual international research center and a place of communication between science, politics and business. IZA is an independent nonprofit organization supported by Deutsche Post Foundation. The center is associated with the University of Bonn and offers a stimulating research environment through its international network, workshops and conferences, data service, project support, research visits and doctoral program. IZA engages in (i) original and internationally competitive research in all fields of labor economics, (ii) development of policy concepts, and (iii) dissemination of research results and concepts to the interested public.

IZA Discussion Papers often represent preliminary work and are circulated to encourage discussion. Citation of such a paper should account for its provisional character. A revised version may be available directly from the author. 
IZA Discussion Paper No. 4028

February 2009

\title{
ABSTRACT \\ Regulation and UK Retailing Productivity: Evidence from Micro Data*
}

\begin{abstract}
We use UK micro data to explore whether planning regulation reduced UK retailing productivity growth between 1997 and 2003. We document a shift to smaller shops, particularly within supermarket chains, following a regulatory change in 1996 which increased the costs of opening large stores. This might have caused a slowdown in productivity growth if firms (a) lose scale advantages, by moving to smaller stores and (b) lose scope advantages if existing organisational knowledge appropriate to larger stores is not perfectly substitutable with the organisational capital required to run smaller stores. Our micro data shows a relation, controlling for fixed effects, between chain-level TFP for multi-store chains and various measures of the size of the stores within the chain. Our results suggest the fall in within-chain shop sizes was associated with a lowering of chain TFP by about $0.4 \%$ pa, about $40 \%$ of the post-1995 slowdown in UK retail TFP growth. The foregone productivity works out at about $£ 80,000$ per small chain supermarket store.
\end{abstract}

JEL Classification: D24, L81

Keywords: productivity, retail, regulation

Corresponding author:

Jonathan Haskel

Imperial College Business School

Imperial College

London SW7 2AZ

United Kingdom

E-mail: j.haskel@ic.ac.uk

\footnotetext{
* We are very grateful for financial support from the ESRC/EPSRC Advanced Institute of Management Research, grant number RES-331-25-0030. Research was carried out at the Centre for Research into Business Activity (CeRiBA, www.ceriba.org.uk) at the Business Data Linking Branch at the Office for National Statistics; we thank the BDL team and ONS for all their help with computing and facilitating research. This work contains statistical data from ONS which is Crown copyright and reproduced with the permission of the controller of HMSO and Queen's Printer for Scotland. The use of the ONS statistical data in this work does not imply the endorsement of the ONS in relation to the interpretation or analysis of the statistical data. This work uses research datasets which may not exactly reproduce National Statistics aggregates. We thank Emek Basker, Roger Betancourt and Howard Smith for very helpful comments. Errors are of course our own.
} 


\section{Introduction}

The speedup in US productivity growth and corresponding slowdown in UK (and EU) productivity growth remains an enduring puzzle of major importance to academics and policy-makers alike. To explain this puzzle much attention has been shifted to the retailing and wholesaling sector, which appears to account for both a large share of the US speedup and UK slowdown. ${ }^{1}$ There are two particular facts that have emerged. First, TFP growth in UK retailing slowed down relative to the US. For example, Basu et al (2003), using as comparable a dataset as possible, find that UK TFP growth in retail was $0.38 \%$ pa $1990-1995$ and $-0.58 \%$ pa 1995-2000, whilst the US figures were 0.49\%p and 3.23\%pa (Tables 4 and 5, based on gross output). Second, and related, as Blanchard (2003) points out, UK labour productivity growth in retailing seems quite reasonable, but TFP growth is slow: why then is the capital investment apparently being used so poorly?

This paper investigates to what extent planning regulation might be responsible for this poor performance in UK retailing. We believe this question to be of wider interest since planning and regulation is cited to be a factor affecting EU retailing productivity growth (Pilat, 1997, McGuckin at el, 2005).

Our investigations begin with two facts. First, in 1996 there was a change in retailing planning regulations in the UK (Barker Commission, 2006, Competition Commission, 2001, Griffith and Harmgart, 2004, Haskel and Sadun, 2005, Sadun, 2008, see also Appendix 1). This change made it much harder for retailers to build large out-of-town stores. Instead, to try to support inner town development, planning permission would only be given for development within cities in the first instance and for out-of-town developments only under special circumstances. Second, after this change (which was further reinforced in 1999) there was a remarkable reversal in the construction of out-of-town retail development. The Barker Report (2006) documents that in 1971 around $65 \%$ of new floor space was constructed in town centres. This fell more or less continuously for 25 years to 23\% in 1996. It rose to over $40 \%$ in 2003 (see Appendix). Associated with this was a marked change in the strategy of UK supermarket chain stores, documented in Griffith and Harmgart (2005). Before 1996, large UK supermarket chains (who account for almost $40 \%$ of retailing employment) were opening "big box" stores on the outskirts of towns. Afterwards,

\footnotetext{
${ }^{1}$ For example, in their study of the US TFP acceleration in the late 1990s versus the UK deceleration, Basu, Fernald Oulton and Srinivasan (2005) find that the wholesale and retail sectors "account" for about three-quarters of the U.S. acceleration in (Domar-weighted industry TFP growth) and one-third of the U.K. deceleration.
} 
UK supermarkets developed and took over inner town small shops ${ }^{2}$. The shift towards smaller stores is apparent in Figure 1 below which compares the histogram of store sizes in UK national supermarket chains (i.e. active in the SIC 521, “Non specialized retail”) in 1997/8 and 2002/3. The histogram shows that over the relatively short time period of four years the median size of a store belonging to a large supermarket chain has fallen from 75 employees to 56 employees.

Overall, the timing of the phenomenon and its uniqueness in comparison to other countries, suggest that the shift towards smaller stores in the UK retail sector - especially in supermarkets has somehow been driven by the regulatory reforms described above. Although a direct comparison is made difficult by the lack of perfectly comparable data ${ }^{3}$, the shift towards smaller stores in the UK retail sector is remarkably different from happened in countries with different planning policies, where retail chains have chosen large store formats to drive their expansion. For example, Jarmin at al (2005) document a continuous trend towards larger stores for the retail sector in the US, a country where zoning regulation is, at least on average, lighter than most European countries. Even within Europe, where planning is typically more regulated, the retail sector has shown a tendency towards larger surfaces whenever this was a feasible strategy. A McKinsey report issued in 1998 draws a direct link between strict planning regulation and the average size of UK grocery stores. Based on in-house data, the report argues that "a typical UK (grocery) store is roughly half the size of a typical US store and two thirds the size of a typical French store” ${ }^{4}$, and that the differences have started to emerge only after a series of restrictive planning reforms were introduced in the UK in the early $90 \mathrm{~s}^{5}$.

\footnotetext{
${ }^{2}$ Interestingly, not all supermarkets changed their strategy in this direction. For example, ASDA/WalMart who had built large stores up to 1996 simply stopped expanding altogether (Griffith and Hamgart, 2005).

${ }^{3}$ Haskel, Jarmin, Motohashi and Sadun (2007) provide a systematic analysis of the retail sector in the UK, US and Japan using comparable micro data. The analysis is available only for 1998 and 2002.

${ }^{4}$ The differences with the French retail sector are intriguing, as the French planning system is also highly regulated. Differently from the UK case, however, planning policy regulates the number of entrants and not their size.

${ }^{5}$ The report also argues that smaller store size in the UK may depend on the ability of UK retailers to exploit space better.
} 
Figure 1: Changes in the Employment Distribution of Small Shops within National Supermarket Chains (vertical lines mark the $10^{\text {th }}, 50^{\text {th }}$ and $90^{\text {th }}$ percentiles of the distribution)

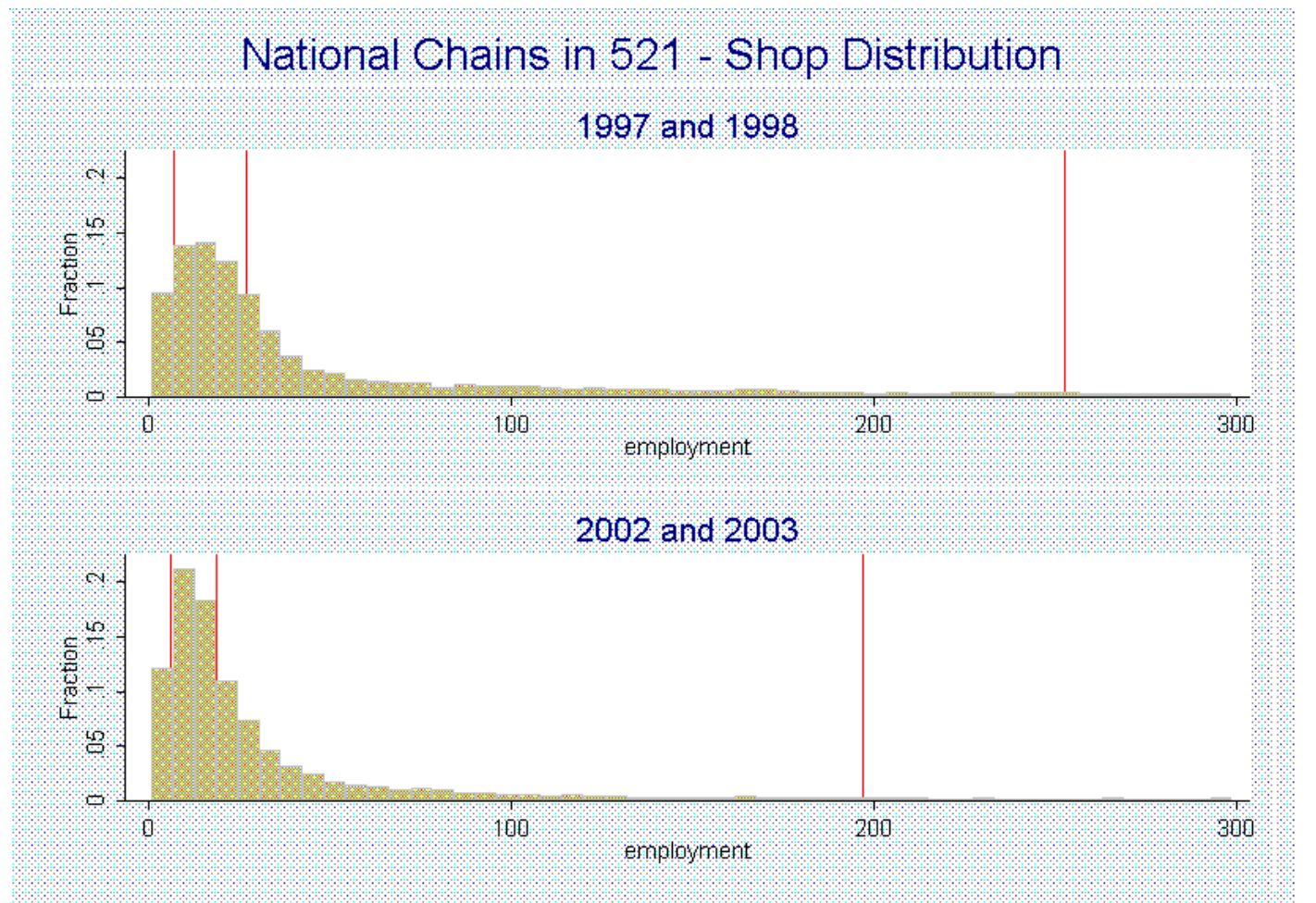

Note: figures are histograms of shop employment for each shop within a national supermarket chain in 1997/8 (top panel) and 2002/3 (bottom panel). A national chain operates in all 11 UK regions. SIC521 is "non-specialised stores", mostly supermarkets. Source: ARD data at ONS.

The main question that we want to explore in this paper is whether the shift towards smaller stores can explain the disappointing productivity performance of the retail sector over the last decade. We assume two potential channels that link average store size and productivity, involving economies of scale and scope. First, if there are (physical) economies of scale ${ }^{6}$ in retailing, the trend to smaller stores would lower measured productivity levels and, during the switch to smaller stores, retard growth. Second, consider economies of scope. Suppose that running a chain of stores requires "organisational capital” to ensure co-ordination. But suppose further that organisational capital is not perfectly substitutable between stores of different sizes. Thus an existing firm characterised by a stock of large stores (as most of UK national retailers where before 1996) forced by regulation to open small stores, is less able to use its organisational capital in these new stores.

\footnotetext{
${ }^{6}$ By which we mean "natural” economies arising from, for example, indivisibilities of opening (i.e. it requires a minimum staff to open a store and staff the cash tills, Oi, 1981) as opposed to what we shall term scope economies due to sharing of managerial expertise and information. Such information sharing is usually referred to as a scope economy e.g. Klette (1996).
} 
This lowers productivity growth as firms adapt their organisational capital to the new profile of store $^{7}$.

We use a unique combination of store and firm level information at the micro level drawn from the official UK Office of National Statistics business surveys (these are the micro data underlying the UK National Accounts) to test our hypotheses about store size and economies of scale and scope. Our main findings are as follows. First, our micro data shows a consistently statistically significant association between firm-level TFP for multi-store chains and various measures of the sizes and the size distribution of the stores within the chain. In particular, we find a positive association with the (log) of median size of within-chain shops and, consistent with this, a negative association between firm-level TFP and the fraction of shops within the chain that are small. The relation is particularly statistically significant in the non-specialised sector (SIC 521), which includes supermarkets. This is precisely the sector where, as we show, large chains are characterized by very large stores and, thus, is particularly likely to have been affected by the change in regulation. The coefficients suggest that the fall in within-chain shop sizes is associated with lowered TFP growth in retailing by $0.2 \%$ pa. This is about $20 \%$ of the post-1995 slowdown in UK retail TFP growth of about 1\% pa documented by Basu et al. Second, to get some idea of the implied valuation of having small shops, we calculate that this TFP represents about $£ 88,000$ per extra small within-chain supermarket store. ${ }^{8}$ A causal link that we think is consistent with our results is that the change in planning regulations in 1996 caused chains to open smaller shops, which led to smaller TFP.

The idea that inputs' heterogeneity might affect productivity is not new: for example, it is widely advanced that at least part of SouthWest Airlines' efficiency is due to having the same type of aircraft, or Wal-Mart having one type of "big box" store. However, we are not aware that this idea has been investigated using retail micro data and herein is the main contribution of our paper. Our findings are of course correlations in the data, although we do control for fixed effects and we do have some preliminary IV estimates.

In closely related work, Griffith and Harmgart (2005, 2008) have used store-level data on the opening of new retail stores from the Institute of Grocery Distribution. There is, however, no productivity information in their data. In their 2008 paper, they add data individual-level food

\footnotetext{
${ }^{7}$ In the future of course productivity stops falling as firms adjust their organisational capital to the new profile of small stores.

${ }^{8}$ Which of course consumers might be quite willing to pay in return for convenience, assortment etc.
} 
prices to estimate the price effects of regulation via competition. We explain these differences in section 4.6. below.

The paper proceeds as follows. In section 2 we document the data sources, in section 4 we describe the econometric work. Section 5 concludes.

\section{Data}

\subsection{Micro data}

Our empirical analysis is based on micro data on retail firms and stores drawn from the the official UK Office of National Statistics business surveys. These are the micro data underlying the UK National Accounts. This section describes the main characteristics of the dataset that we employ in the econometric section.

The UK business data is the Interdepartmental Business Register (the IDBR). This business register is compiled using a combination of tax records on VAT and PAYE, information lodged at Companies House, Dun and Bradstreet data and data from other surveys. The IDBR tries to capture two broad measures. First, it tries to measure the structure of ownership of businesses using three aggregation categories: "local units (LUs)”, “enterprises” and “enterprise groups”. A "local unit” is a single mailing address, so this is best thought of as a shop or store. An "enterprise" is a chain of local units/shops under common ownership (e.g. a chain of supermarket stores). An "enterprise group” is a group of enterprises under common ownership (e.g. a chain of both supermarket stores and garden centre stores). The second part of data that the IDBR holds is turnover and employment data. This is based mostly on tax data (plus old records from previous inquiries). Output information on the IDBR comes from VAT records if the original source of business information was VAT data. Employment information comes from PAYE data if that is the source of the original inclusion. Thus, if a single-local unit enterprise is large enough to pay VAT ((the threshold was $£ 52,000$ in 2000/01) it would have turnover information at the enterprise and local unit level. On the other hand, if it does not operate a PAYE scheme, it will have no employment information. However, employment data is required to construct sampling frames and hence is interpolated from turnover data. For the multi-local unit enterprise, no turnover information will be available for local units, since most multi-local unit enterprises do not pay VAT at the local unit level. If the PAYE scheme is operated at the local unit level, it would have independent employment data.

There are two other ways in which more employment and output data are gathered. The first is if the business is included Annual Register Inquiry (ARI) and the second if it is included in 
the Annual Business Inquiry (ABI). The ARI is designed to maintain the business structure information on the IDBR (Jones, 2000, p.51). It began in July 1999 and is sent to large enterprises (over 100 employees) every year, to enterprises with 20-99 employees every four years and to smaller enterprises on an ad hoc basis. The ARI currently covers around 68,000 enterprises, consisting of about 400,000 local units. It asks each enterprise for employment, industry activity and the structure of the enterprise, including having to report employment of its local units. The ABI is the official ONS business survey, based on the IDBR, to ask for inputs and outputs and so generate value added for the national accounts (the Annual Respondents Database, ARD, consists of the panel micro-level information obtained from successive cross-sections of the ABI). The ABI covers production, construction and some service sectors, but not public services, defence and agriculture. The ABI is covered by the Statistics of Trade Act, 1947, and therefore the firms are obliged by law to provide data if they get a form. ${ }^{9}$ To reduce compliance costs however, the ABI is not a Census of all local units. This is in two regards: aggregation and partial sampling. Regarding aggregation, enterprises normally report on all their LUs jointly. This is called a "reporting unit" (RU) but is typically an enterprise; for convenience we shall call it a chain or firm. Regarding sampling, to reduce costs, only reporting units above a certain employment threshold (currently $250^{10}$ ) are all sent an ABI form every year. Smaller reporting units are sampled by size-regionindustry bands. ${ }^{11}$

The questions asked on the ABI for retailing vary somewhat. Firms are required to provide details on turnover (total and broken down in retail and non-retail components, and by commodity sold), expenditures (employment costs, total materials and taxes), items defined as work in progress, capital expenditures (separately for acquisitions and disposals). They also have to answer sections related to import or export of services and on the use of E-Commerce and employment, with further data on part-timers. However, the survey form can be sent in a long or in a short format. The main difference between the two types of formats is that in long format firms are required to provide a finer detail of the broad sections defined above. For instance, in the long format firms break down their disposals and acquisitions information about 20 different items, whereas in the short format they only report the aggregate values. Also, in the long format, firms

\footnotetext{
${ }^{9}$ Companies who have to fill out a form can refer to:

http://www.statistics.gov.uk/about/business_surveys/abi/default.asp for help and information.

${ }^{10}$ The threshold was lower in the past. See Criscuolo, Haskel and Martin (2002) for more details.

${ }^{11}$ The employment size bands are 1-9, 10-19, 20-49, 50-99, 100-249, the regions are England and Wales combined, Scotland and Northern Ireland. Within England and Wales industries are stratified at 4 digit level, NI is at two digit level and Scotland is at a hybrid 2/3/4 digit level (oversampling in Scotland and NI is by arrangement with local executives). See Partington (2001).
} 
answer on questions such as the total number of sites and, on occasion, the amount of squared metres they consist of. Other reported data at the RU level are total employment, wages and input costs and investment. The investment data are used to build up a capital stock database using the perpetual inventory method.

To summarise, our retailing productivity data consists of ABI data at the chain/firm level, which is typically the RU. However, we do know employment and location information for the stores/shops/LUs within the RU. Thus we can examine how the productivity of the RU relates to RU inputs, such as bought in materials, capital etc. but also to the characteristics of its stores (LUs). The reporting unit/local unit issue raises a number of measurement issues (econometric issues are discussed below). First, although an enterprise group can in principal consist of a number of lines of business, in practice however retailers in an enterprise group tend to report in one reporting unit i.e. retailers of food and hardware report in the same reporting unit. ${ }^{12}$ Second, many of the larger retailers are vertically integrated; supermarkets for example have both their own shops and transport facilities (none on our data had food production). This is coded on the data as follows: the RU will have a number of LUs classified to retailing and a number classified to wholesaling. Thus below we measure the fraction of small stores by the fraction of local units classified to retailing only. In our robustness check, we also look at vertical integration and measure vertical integration, following Aghion and Griffith (2006), by the fraction of LUs classified to wholesaling. Third, there is an issue with takeovers depending on how the shops of the new entity are classified. As a matter of data however, there are in fact rather few takeovers among the big stores in our dataset, the takeover wave coming after 2003. ${ }^{13}$ Finally, we also note there is a problem with capital stocks. Capital stocks are built at the RU level using a perpetual inventory method based on RU-level

\footnotetext{
${ }^{12}$ The median number of RUs per enterprise group was 1 over our data period, with the average slightly above 1.

${ }^{13}$ The details are as follows. Suppose a multi-store retailer takes over another single store. The multi-store retailer is gathered in one enterprise group and one RU each with their reference numbers, likewise the target store. After the takeover, the target store retains its LU and RU number, but its enterprise group (ENT) number changes to that of the acquirer. The same happens if the target is a chain of $n$ stores: they keep their $n$ LU numbers, their single RU number, but the ENT number becomes that of the acquirer. The exception is if the target is $m$ shops out of a total $n$, then the $m$ shops keep their LU numbers but are absorbed into the RU of the acquirer. All this has the following consequences. We work at reporting unit level and look at the productivity of an RU when its size distribution of LUs changes. In the case when the RU simply builds smaller shops, or acquires shops that were previously a subgroup of a rival RU then there is no problem: the LUs within the RU change and the RU aggregates change consistently. There is a problem however if the RU buys all the LUs of a rival RU (or a single RU): then the size composition of the RU does not change, nor does the output since the two RUs stay in existence. Rather the output and size composition of the ENT changes. This suggests that it might be preferable to work at the ENT level to capture the third case. One problem with this is that ENT numbers turn out to be very volatile, whereas the RU numbers are much less so (The ONS does not collect the enterprise group numbers independently, rather it relies in information from the Dun and Bradstreet "Who owns whom?" dataset. If this is volatile or is noise is induced by transferring these data to the ABI data this could account for the volatility of the ENT reference codes.). Thus we preferred to work initially at the RU level, although we will explore ENT effects in more detail in the robustness checks below.
} 
investment data (no investment data exists at other levels). If then a firm buys an individual small shop this will not show up as investment. Thus the measured capital stock understates the true level after the acquisition (since the new capital in the acquired shop is not added into the capital stock term), and since output rises, TFP spuriously increases. Since in this example the fraction of small firms falls, then this bias means we understate (bias towards zero) any true negative relation between store size and measured TFP.

\subsection{Industry structure}

Table 1 is shows information on the structure of the UK retail sector. Given the heterogeneity of the sub-sectors that are classified under Retail (SIC 52), we also provide basic statistics by 3 digit SIC industry. We have 7 industries, with the "non-specialised", SIC521, covering supermarkets. The descriptions of the industries set out in the table note. The data show employment for 1997/8 and 2002/3 (i.e. the average of the start and end years; averages taken to smooth out jumps in the data). The largest sectors are in terms of employment are "Non specialized retail” (supermarkets, SIC521) and "Other specialized retail" (SIC524), followed by "Food" (SIC522) and "Pharmaceutical" (SIC523). The largest in terms of stores are "Other specialized retail”, "Non specialized retail” and "Food". The final columns show the 15 firm concentration ratio, with the highest concentration in “Non specialized retail” and “Other specialized”.

In Table 2 we start exploring the role of within sector firm heterogeneity by dividing the sample of stores according to the number of stores they own. We define three types of retail firms: "stand-alone" or "mom and pop" stores which are single owned shops, "small chains" which are chains of stores operating in at least nine (out of the UK's 11) regions and "large chains”, operating in all regions. ${ }^{14}$. Table 2 shows how shares of employment in different retail chains, left hand panel, and share of stores, right hand panel, have evolved over time. Looking at supermarkets first, the top row shows the share of employment has fallen fractionally in stand-alone stores, fallen more in small chains and risen in large chains. The same is true in terms of shops, with a particularly sharp fall in the share of stand-alone shops. The general pattern is repeated in all sectors, with the exception of Food and Pharmaceutical. In these sectors the employment share of stand-alone shops has fallen only fractionally and the share of large chains has remained flat (in Food) and only risen

\footnotetext{
${ }^{14}$ See Jarmin et al (2005) and Ellickson (2005) for a similar classification of retail firms.
} 
very slightly in pharmaceuticals ${ }^{15}$. The changes in the shop distribution are also similar, with a slightly less pronounced rise in the share of large chains.

Table 3 shows in more detail how the distribution of shop size within chains has changed, using a number of different measures. All data in this table are for chains, and we distinguish once more between small and large chains. The industries are Supermarkets, Food, Other Retail Stores and the final category is the rest of the industries grouped together (due to small sizes). The first column shows the standard deviation of shop sizes. For small chains, this shows an increase over the period in supermarkets and other, a small increase in food and a decline in the grouped industries. For large chains, the change is different: there has been a fall in supermarkets, food and the rest but a rise in pharmaceuticals. The second column of Table 3 shows the fraction of small shops in chains. In devising this measure, there are a number of issues. The problem here is to specify the benchmark for small. One possibility is to use some percentile point in a base period, but this might be regarded as too discrete and the choice of percentile point is to some extent arbitrary. Another issue is that if there is some technological force that is expanding all store sizes then benchmarking against a previous point would not account for this: rather, one would want to benchmark against a measure like average size in the market. As it turned out all the measures gave rather similar answers, so the number used in this panel is the fraction of shops below the median size of the chain in the base period (1997-8). For large chains the picture is one of a rise in the fraction small in supermarkets, regardless of measure, but falls in other industries. For small chains there has been either little change or a fall. Finally, the other columns report the size of store at the $25^{\text {th }}, 50^{\text {th }}$ and $75^{\text {th }}$ percentiles of the store distribution. ${ }^{16}$ Again, the picture is most pronounced for large chains of supermarkets, namely a fall in all sizes at all points in the distribution. The median store size has fallen from employing 72 persons to 57 , whilst the size at the $75^{\text {th }}$ percentile has fallen from 141 persons to 117 persons. For other industries there is much less change. Median sizes have hardly changed at all, although there has been a slight decline in the $75^{\text {th }}$ percentile for large chains. ${ }^{17}$

\footnotetext{
${ }^{15}$ Interestingly, the sales of Pharmaceuticals in the UK is regulated.

${ }^{16}$ We can calculate two versions of this statistic. We can simply take all S stores, regardless of firm, and compute the median or other size, giving one measure for all stores. Or, we can take all stores, allocate them to their firm, and calculate a particular percentile, say the median for each of the F firms, and finally take the average of this figure, say the median, over the F firms. This second method is used in the Tables and corresponds to the regression where we need a median per firm. The first method is used to construct the first figure.

${ }^{17}$ As a matter of information, our regression sample is not quite this picture, since with fixed effects we use firms who are present in at least two periods. But the changes are similar, namely a fall in shop sizes for supermarkets and little change elsewhere).
} 
These data suggest that the change to smaller shop sizes within chain store size is largely confined to large chains in supermarkets. Median store sizes in small chains have risen in all industries and for large chains in industries other than supermarkets, they are flat. A number of points are worth making on this finding. First, this is still of interest, since large supermarket chains account for a large share of overall retailing activity (37\% of value added and 31\% of employment). Second, technical progress might have been expanding store sizes and hence the change to slightly larger stores outside large chain retailing might still be lower than it would otherwise have been. Third, it is plausible that the move to inner-town stores only affected size in the non-specialised industry. As Table 3 shows, store sizes in large non-specialised chains are by far and away higher than those in other industries (even in large chains). Thus it is realistic to think that such regulation might have been binding on only this industry.

\section{Theory}

Our econometric work examines the correlation between the distribution of store sizes within chains and productivity of the chain ${ }^{18}$. This section is designed to help the interpretation of this correlation.

Retail chains choose a mix of inputs (capital, labour and material) to produce. We consider a store as a specific type of capital, characterised by a location and a dimension (square footage). As size and store location tend to be correlated (peripheral areas tends to attract larger stores due to land costs) in what follows we introduce the simplification that a store can be fully characterised by being small or large. Under this assumption, the production function of a representative retail chain can be expressed as follows:

$$
Q_{i t}=f\left(Z_{i t}, S^{L}{ }_{i t}, S^{S}{ }_{i t}\right)
$$

Where Q represents chain level output, Z are the standard inputs used in production (capital stock excluding stores, labour and material) and $S^{L}$ and $S^{S}$ are, respectively, the total number of large and small stores owned by the firm. The subscript $i$ denotes chain or firm. The reason for considering large and small stores as distinct inputs stems from the fact that, in principle, their marginal productivity may differ, i.e.:

\footnotetext{
${ }^{18}$ Strictly speaking, since we allow for fixed effects, it will be the change in the distribution and change in productivity.
} 


$$
\frac{\partial Q}{\partial S^{L}} \neq \frac{\partial Q}{\partial S^{S}}
$$

The literature has provided a number of reasons suggesting that larger stores may indeed be associated with higher marginal returns, i.e: $\partial Q / \partial S^{L} \geq \partial Q / \partial S^{S}$. The simplest story is one of economies of scale at the store level. As argued by Oi (1998) economies of scale at the store level may simply be due to the existence of fixed inputs (labour, parking, advertisement, management etc.) which generally characterise the activity of retail stores ${ }^{19}$. Oi describes also a second possible source of economies of scale, defined as "economies of massed resources", which arise as a combination of consumers effectively entering retailers' production functions and stochastic demand. Economies of scale at the store level may translate into productivity benefits at the firm level, at least under the assumption that they are not offset by potential diseconomies at the firm level arising from the joint coordination of sets of larger stores. In fact, the literature has emphasized that economies of scale at the store level might actually be magnified when considered at the firm level, due to potential interactions between sets of large stores and other inputs. Holmes (2002) provides a model where large stores arise as an optimal choice due to complementarity with new information technologies (bar codes) and integrated distribution networks. Basker et al (2007) describe large stores as an optimal choice in a model where store size is synonymous for breadth of product lines offered and consumers are characterised by preferences for “one stop shopping”. In their model increasing store size is in a complementary relation with retail chain expansion (number of stores) via fixed costs in what they define "chaining technology", i.e. the ability of retailers to coordinate multiple stores.

Economies of scope might also account for a connection between store size and firm productivity which varies by store size. Suppose that retail chains have a stock of knowledge or organisational capital that affects productivity. But suppose that some of that organisational capital is concerned with running large stores and some with small stores. It is plausible to assume there are economies of scope in such knowledge, but such knowledge may not be perfectly substitutable

\footnotetext{
${ }^{19}$ This is also the line of argument followed by the McKinsey report into the UK grocery sector (1998). They mention as fixed or quasi fixed inputs management costs (about 10\% of total labour costs) and goods flow (stocking of goods in the aisles).
} 
between stores of different sizes.20 This kind of effect is presumably part of the reason why low cost airlines like Southwest fly one type of aircraft.

Given this simple set up, the relationship between store size, regulation and firm level productivity can be analysed within a framework of optimal investment choice ${ }^{21}$. Consider that case of a price-taking ${ }^{22}$ retail firm that maximises its profits deciding in each period the optimal amount of inputs and the optimal number of small and large stores it wants to purchase ${ }^{23}$. The introduction of restrictive planning rules concerning the openings of large retail stores can be seen as an increase in the price of large stores as opposed to small stores ${ }^{24}$. Everything else equal, planning reform will then imply increase in the (shadow) price of opening a large store, and a reduction in investments in large stores. Under the assumption that $\partial Q / \partial S^{L} \geq \partial Q / \partial S^{S}$, this will translate into a lower overall firm level TFP.

The negative effect of regulation on TFP would be even stronger if the production function is characterised by complementarities between large stores and other inputs which are costly to adjust. For example, a retail chain might have a distribution network based on large trucks, which suits a network of large stores in peripheral areas, but it might be extremely difficult to manage with smaller stores in town centres. To the extent that the firm cannot change its distribution network instantaneously, the move towards smaller stores lowers productivity growth. The negative effect on productivity is in this case a transitory phenomenon, and it will eventually disappear as firms adapt their organisational capital to the new profile of stores.

\footnotetext{
20 To make matters concrete, suppose that the knowledge is about the numbers of product lines and delivery arrangements which is written in a handbook. It is plausible that such knowledge is informative across different stores, but that the pages describing arrangements for the large stores are not identical to those for small stores.

${ }^{21}$ See for example the basic investment model in Bond and Van Reenen (2003).

${ }^{22}$ The price taking assumption simplifies considerably the model. Beresteanu and Ellickson (2006), Aguirregabiria et al (2006) among others provide models of retailers' expansion and competition with different strategic settings and explicit demand systems.

${ }^{23}$ Expansion can be by building new shops or taking over other shops (the relative price of which depends on the price of land and the extent to which knowledge in one firm can be transferred to a brand new shop built within the firm and a shop acquired by the firm).

${ }^{24}$ It is in these terms that retailers have described the reform to the Competition Commission (2000). The Barker Review (2006) estimates the average cost of a planning application at about $£ 100.000$. The Competition Commission (2000) documents that the 1996 reform was associated with increased uncertainty in the planning process and heightened application costs due to the introduction of the "sequential test" and the "test of need", i.e. after 1996 retailers have to prove the need for their new store in the chosen area and the impossibility of opening an alternative store in an in town location.
} 


\section{Econometric work}

\subsection{Specification and measurement}

To simplify the analysis, we assume that large and small stores enter the production function in the following form:

$$
Q_{i t}=f\left(Z_{i t},\left(S^{S}{ }_{i t}+(1+\alpha) S^{L}{ }_{i t}\right)\right)
$$

where the total number of stores is $S_{i t}=S^{L}{ }_{i t}+S^{S}$ it and $(1+\alpha)$ is the marginal productivity of large stores relative to small stores. Simple algebra implies that we can rewrite (5) as:

$$
Q_{i t}=f\left(Z_{i t}, S\left(1+\alpha \frac{S^{L}{ }_{i t}}{S_{i t}}\right)\right)
$$

Based on (6), in order to analyse the relationship between store size and measured productivity it suffices to obtain measures for $\mathrm{S}$ and the share or large stores owned by the retail chain, plus of course all the other inputs included in Z.

Regarding the total number of stores owned by chain $i$, these are included in the firm level capital stock. To obtain a measure of the share of large stores we have to take a number of steps. First, as the ARD does not contain information on the square footage of retail stores, we use employment at the store level to approximate for the average size of a store. Second, we need to define what we mean for a large store. We proxy for the share of large stores belonging to retail chain $i$ using moments drawn from its stores' distribution. For example, everything else equal, the size distribution of the $j$ stores belonging to the chain that opens a new large store will shift to the right. Defining $\phi\left(S_{i, t}\right)$ as a function that maps moments from the size distribution of stores belonging to chain $i$ at time $t$, i.e $S_{i . t}=\left\{S^{1}{ }_{i, t}, S^{2}{ }_{i, t}, \ldots, S^{N}{ }_{i, t}\right\}$, we rewrite (6) as:

$$
Q_{i t}=f\left(Z_{i t}, S\left(1+\alpha \phi\left(S_{i, t}\right)\right)\right)
$$


The main measures that we use are median store employment and - symmetrically - the fraction of stores that are below the median observed at the beginning at the sample. We also experiment with higher moments of the store distribution, using the coefficient of variation and the interquartile range.

Second, we specify the $\mathrm{Z}$ and $\mathrm{Q}$ variables in (7), as the usual production function arguments of chain-level capital, employment and material use, with Q being gross output. There are clearly a number of issues here. First, the measurement of retail output and estimation of relevant input elasticities raises a set of conceptual issues that are discussed in Appendix 2. Here we follow a standard gross output production function approach with fixed effects to try to control for as many unobservables as possible. Second, a measure of capital here is build up via the perpetual inventory method using data on investment in plant, buildings and machinery. This does not by any means measure capital in the firm since much of the effective retailing capital stock is due to factors like, for example, floor area. In addition, the investment data is at the firm level and not the shop level so that the acquisition of shops will not show up as investment. Thus from the point of view of measurement, it is perfectly possible that our shop size variables are picking up aspects of the mismeasured capital stock, rather than the organisational capital stock. It could be argued however that this may not matter very much since we will be unable to distinguish between conventional and physical capital in any case.

Third, as noted above, Betancourt (2004) has argued that sales of a retail store are affected by distribution services such as ambience, product assortment, accessibility of location, assurance of delivery and information. Like other studies, we do not have detailed measures of these factor and so proceed as follows. First, we include regional and industry dummies to control for any common regional and industry level of distribution services. Thus for example, we do not compare food retailers with second-hand car dealers but compare within 4-digit industries. Second, we enter a dummy for whether the shop is part of a national chain or not, which should additionally control for ambience-type effects. Third, we also enter fixed firm effects so that we are comparing changes in sales, controlling for other things, rather than levels: to the extent that factors such as ambience and location convenience remain fixed, this should be controlled for. See Appendix 2 for a detailed discussion. 


\subsection{Econometrics}

Given the steps described above, and a standard Cobb-Douglas assumption on the production function $^{25}$, we end up estimating a log linear equation of the following form for firm $i$ :

$$
\ln Q_{i t}=\sum_{Z=K, N, M} \gamma^{Z} \ln Z_{i t}+\gamma^{s} \phi\left(S_{i, t}\right)+\gamma_{1} C H A I N_{i t}+\gamma_{2} M N E+\lambda_{i}+\lambda_{T}+\lambda_{I}+\lambda_{R}+\varepsilon_{i t}
$$

With a panel of data we shall estimate (8) by OLS and OLS with fixed effects. The econometric issues involved are discussed in, for example, Griliches and Mairesse (1986). A number of points are worth making. First, our primary focus is $\gamma^{\mathrm{S}}$, the coefficient on $\phi$. If regulation determines $\phi$ and if such regulation is orthogonal to firm characteristics then the estimated $\gamma^{S}$ is unbiased. If, however, this orthogonality condition fails, the coefficient on $\phi$ will be biased. Consider the case where better managers both raise productivity and employment, a partial explanation as to why large firms are more productive. This would tend to make OLS estimates of productivity and store size overstated. On the other hand, if better managers are needed to run chains with different mixes of stores, OLS would understate the relation between productivity and store size and overstate between the relationship between productivity and store dispersion ${ }^{26}$. To control for this type of biases we use fixed effects, thus the impact of $\phi$ will be biased only if changes in unobserved managerial skill cause both changes in $\phi$ and changes in TFP.

Second, unbiased estimation of the effect of input quantities comes from exogenous factors that cause them to vary, usually taken to be factor prices. Such factor prices are not available and indeed constructing them would be hard since the chain data is aggregated employment over a number of different locations. An alternative is to use lagged quantities as instruments, but in a fixed effect regression over a short period such lags are unlikely to be powerful instruments. Since the estimation of these parameters is not our central concern we do not pursue this issue here. ${ }^{27}$

Third, we do not have firm-specific output or input prices, rather four-digit industry prices. The consequences of this for production function estimation are explored in e.g. Klette and Griliches (1996) who point out that omission of firm-specific output prices, under the assumption

\footnotetext{
${ }^{25}$ We also exploit the fact that $\ln (1+x) \approx \ln (x)$. Note that the total number of stores is included in the capital stock $\mathrm{K}$ and that the specification abstract from possible complementarities between the share of large stores and other inputs.

${ }^{26}$ There is likely measurement error in the reporting of store employment as well. If it is classical then that would potentially bias the effect toward zero. Whether it is classical is not clear however, since we might assume that measurement error is greater the more stores that a firm has and the more new stores a firm opens (since to some extent the ONS checking procedures and forms are based on previously recorded store numbers).

${ }^{27}$ Still another alternative is of course to use an Olley-Pakes (1984) type procedure but this relies on particularly strong identification assumptions, see e.g. Bond and Soderbon (2005) and the discussion in Hellerstein and Neumark (2005).
} 
that demand is Dixit-Stiglitz introduces a term in $\left(\mathrm{p}_{\mathrm{i}}-\mathrm{p}_{\mathrm{I}}\right)$ in the error term, so that cross-sectional comparisons of TFP reflect both differences in technology but also prices deviations. Similarly, if there input prices are firm-specific then the error term also contains a term in $-\gamma^{\mathrm{Z}}\left(p_{i}^{\mathrm{Z}}-p_{I}^{\mathrm{Z}}\right)$ for the Z'th input. Thus cross-sectional comparisons of TFP reflect also the ability of firms to source inputs cheaper than others (such firms will have higher measured TFP). This is then another reason to include fixed effects. Thus the $\gamma \mathrm{s}$ are biased to the extent that deviations in within-firm scale measures from the mean are correlated with deviations of output prices net of input-elasticity weighted deviations of input prices.

The direction or magnitude of this bias is not clear. In the levels, it seems reasonable to assume that larger firms can source cheaper inputs, giving them higher measured TFP. Since this level effect is controlled for, bias would occur to the extent that changes in $\phi$ are correlated with changes in $-\gamma^{\mathrm{Z}}\left(p_{i}^{\mathrm{Z}}-p_{I}^{\mathrm{Z}}\right)$. Thus any effect of median size (as an example of an $\phi$ measure) on measured TFP would be biased upwards if firms with rising median sizes were achieving higher input price gaps. We might imagine that more monopolistic firms would be able to achieve higher input price gaps, and that this might be more likely in large firms. However, large firms have had falls in median store size, which would induce a negative correlation between median size and price gaps, which would imply our effects are understatements of the true effect.

Fourth, a related effect due to lack of firm-specific prices comes about with product mix. Anecdotal evidence suggests that smaller stores in large chains often carry different (high value) product mixes and do not feature special offers in the way that large stores do. Suppose then that large stores offer both high and low price baskets of goods but that only large stores feature discounts. Thus, in obvious notation the large stores are offering a basket with value $\mathrm{B}_{\mathrm{L}}=\mathrm{P}_{\mathrm{H}}(1$ s) $\mathrm{Q}_{\mathrm{H}}+\mathrm{P}_{\mathrm{L}} \mathrm{Q}_{\mathrm{L}}$ whereas the smaller stores offer a basket $\mathrm{B}_{\mathrm{S}}=\mathrm{P}_{\mathrm{H}} \mathrm{Q}_{\mathrm{H}}$. Denote the number of stores in a chain as $\mathrm{N}$, with $v$ the fraction of small stores, in which case the firm level basket, which is what we measure is $\mathrm{B}_{\mathrm{F}}=\mathrm{N}\left((1-v) \mathrm{B}_{\mathrm{L}}+v \mathrm{~B}_{\mathrm{S}}\right)$. Thus in the cross-section there will be a correlation between the fraction of small stores and the revenues from full price high-margin goods. If these revenues are higher ${ }^{28}$ then chains with more small stores would have higher measured output. This works in the opposite direction to what we have found.

Fifth, aggregation. As discussed, our data is at chain or firm level. We postulate a loglinear relation between firm-level outputs and inputs, and within-firm measures of input

\footnotetext{
${ }^{28}$ It would seem reasonable that they are higher i.e. the demand at these stores is sufficiently inelastic so revenue is large even with the lack of sale prices, since this would cover higher land rents at such stores who are e.g. in centres of town, or in stations and airports where presumably space is priced at a premium.
} 
distributions. However, by definition, the log of chain-level output or input, which is the log of the sum of outputs or inputs is not the same as the sum of the logs of outputs or inputs. Thus we have to be careful that the within-firm measures do not appear just due to aggregation. To examine this we proceed as follows. Consider a simple case where each shop $j$ within a chain has a CobbDouglas relation of the form $Q_{j}=N_{j}^{\alpha} K_{j}^{\beta}$. We only observe $Q_{i}=\Sigma_{j} Q_{j}, K_{i}=\Sigma_{j} K_{j}, N_{i}=\Sigma_{j} N_{j}$ but for each chain $i$ we do observe the $\mathrm{N}_{\mathrm{j}} \mathrm{s} \forall j \in i$. Let us start by assuming that $\mathrm{Q}, \mathrm{Y}$ and $\mathrm{N}$ are log- normally distributed within the firm. Making use of the relation that for a log-normally distributed variable $\log \left(\Sigma_{\mathrm{j}} \mathrm{X}_{\mathrm{j}}\right)=\Sigma_{\mathrm{j}}\left(\log \mathrm{X}_{\mathrm{j}}\right)+\sigma_{\log \mathrm{X}}^{2}$, where $\sigma^{2} \log \mathrm{X}$ is the standard deviation of $\log \mathrm{X}$, we can write the firm-level (which is what we observe) relation between inputs and outputs as $\ln Q_{i}=\gamma^{N} \ln \left(N_{i}\right)+\gamma^{K} \ln \left(K_{i}\right)+\frac{1}{2}\left(\sigma_{\log Q_{j}}^{2}-\gamma^{N} \sigma_{\log N_{j}}^{2}-\gamma^{K} \sigma_{\log K_{j}}^{2}\right)$.

Following these steps, equation (8) becomes:

$$
\begin{aligned}
& \ln Q_{i t}=\sum_{Z=K, N, M} \gamma^{Z} \ln Z_{i t}+\gamma^{S} \phi\left(S_{i, t}\right)+\frac{1}{2}\left(\sigma^{2} \log Q_{i}-\sum_{Z=K, N, M} \gamma^{Z} \sigma^{2} \log Z_{i}\right)+ \\
& +\gamma_{1} C H A I N_{i t}+\gamma_{2} M N E+\lambda_{i}+\lambda_{T}+\lambda_{I}+\lambda_{R}+\varepsilon_{i t}
\end{aligned}
$$

This shows that the relation between observed log firm output and observed log firm inputs in (8) has an extra term in it, namely the within-firm variance of log output net of the sum of the output elasticity weighted within-firm variances of log inputs. Thus (9) shows that the use of logs does indeed induce a relation between log output and within-firm input distributions. It is important to note however, that the induced term is not, even in this simple case, a simple dispersion measure of one of the inputs, such as the median or standard deviation, but is rather the gap between the dispersion of output and the (weighted) sum of dispersion of inputs. Thus the question is: to what extent might our postulated relation between chain log output and within-chain store size dispersion simply arise due to aggregation?

The bias to $\gamma^{\mathrm{S}}$ depends upon the correlation between this and the gap term (with fixed effects, strictly between changes in $\gamma^{S}$ and changes in the gap). Even in levels, it is not clear whether this correlation is positive or negative. Unobservably good firms, who might have high $\phi$, for example, might have a positive or negative gap. The reason is the gap depends on whether (unobservably) better managers are better able to affect output variation net of input variation. One view would be that good firms keep, for given input variation, output variation low, since customers might dislike 
output variation. Or it might be that good firms keep input variation low (e.g. managing absenteeism) and so the gap is positive. Given this uncertainty, it would seem even harder to sign the correlation in the differences. ${ }^{29}$

\subsection{Results}

Table 4 sets out our results. Since we focus on the impact of the within-firm size distribution, we use only multi-store firms in this table. Thus the first column sets out a regression of output on the standard inputs with a dummy for whether the firm is a national chain or not (the omitted category is a regional chain) on 7,469 firms. The sum of the coefficients on the conventional inputs (0.982) indicates decreasing returns and the national chain dummy indicates a (statistically insignificant) positive TFP advantage to being a national chain. To help interpret these numbers, column 2 shows a fixed effects regression (on the same sample of firms). Here the coefficients on the inputs are reduced somewhat (except for $\operatorname{Ln} N$ ) and the national chain dummy indicates a (statistically significant) positive TFP advantage, relative to regional chains, of about $7 \%$.

The fall in the input coefficients, particularly of capital, are in line with the well-known exacerbation of measurement error with fixed effects and might therefore suggest that we should not use the fixed effect specification. However, there are presumably a host of unobserved distribution services and thus it would seem preferable to include the fixed effects since the distribution services offered in shops is so hard to control for.

In the next columns then, we consider within-firm employment measures with fixed effects. Column 3 adds log median size, which is positive and significant, suggesting that a $1 \%$ reduction in median store size is associated with $0.0261 \%$ decrease in productivity. Column 4 and 5 add the share of small stores in the firm by number and employment respectively, both of which are significantly negative (respectively -0.0712 and -0.0669 ), suggesting that an increase in the number

\footnotetext{
${ }^{29}$ As a matter of data, we only have within-firm data on $\mathrm{N}$ and so can only investigate the correlation between log median shop size for each firm and $\sigma^{2} \log$ (the variance of shop sizes within firms). This is 0.20 , significant at the $1 \%$ level. Finally, note this equation above is derived when the inputs are log linear and the output elasticities in the storelevel production function do not vary across stores in a chain. In the more general case, one still obtains a relation being the gap between the dispersion of output and the output-elasticity weighted dispersion of inputs. In the constant output elasticity case with just one input $X$ Albuquerque (2003) shows the equivalent of the last term on the right-hand side of (9) to be $\bar{L}(\mathbf{Y})-\gamma \bar{L}\left(\mathbf{X}_{i}\right)$ where $\bar{L}(\mathbf{Y})=\ln (\bar{Y} / \tilde{Y})$ where $\bar{Y}$ and $\tilde{Y}$ equal the arithmetic mean and geometric mean of $Y_{i}$ across the stores within the chain $j$ respectively and similarly for $X$, and $\gamma$ is the output elasticity of $\mathrm{X}$. In the case of the log-normal distribution the relation between the arithmetic and geometric mean implies the expression becomes that in (9). See Alburquerque (2003, expression (4)) for an expansion of this with more factors the term involves additional output-elasticity weighted terms, and with varying $\gamma \mathrm{s}$ across stores within a chain, additional terms in the covariance of the log level of inputs (relative to the chain average) and the store-specific $\gamma$ (relative to the chain average). These aggregation results are also consistent with Lewbel (1992) results on scale-invariance.
} 
of stores below the beginning of period median is associated with lower overall firm productivity. The next two rows show similar effects, whilst controlling too for median size. The final columns look at the effect of dispersion in within-chain store sizes, controlling for median store size. The dispersion measures are the coefficient of variation of within-firm store size and the (log) of the IQR, both of which are positive, but statistically insignificant.

All this suggests that, controlling for overall firm size, fixed effects and other inputs, withinfirm store sizes have a statistically significant association with firm productivity. Firms with smaller within-firm store sizes (measured either as median size or fraction of small firms) are associated with lower productivity.

To explore the role of industry heterogeneity, we run separate regressions for each threedigit SIC. This also enables us to decompose better the effects on productivity given that the share of small firms has changed slightly differently across sectors. It is worth noting however sectors 521, 522 and 524 are the biggest subsectors in terms of employment and so we amalgamated the remaining sectors due to small sample problems. The top row of Table 5 reports the coefficient on $\log$ median store size for each 3 digit sector (all other regressors are not reported). The second and third rows report coefficients on the fraction of small shops using measures by employment and number of stores respectively. The table suggests that the results are mainly driven by "Non specialised retail” (SIC521) and “Other specialised retail” (SIC524, this subsector excludes retail of Food and Pharmaceutical goods), which together represent $86 \%$ of total retail employment and $92 \%$ of total retail value added. For supermarkets (SIC521), there is a strong positive effect from median size, with no significant effect from the fraction of small shops. For "Specialised Retail" (SIC524), there is also a strong positive effect from median size, and a negative effect from the fraction of small shops. The other sectors have no particularly statistically significant effect.

\subsection{Robustness checks and IV}

Finally, we return to the overall table and in Table 6 we set out some robustness checks on the sample of Table 1 . Column 1 and 2 repeat, for convenience, the benchmark specification from Table 5 for, respectively, median store employment and percentages of small stores. We next consider robustness. First, it might be that our results capture some unobserved effects due to the distribution network of retail chains, i.e. vertically integrated firms have higher TFP and larger 
stores $^{30}$. To explore this potential source of bias, in columns 3 and 4 we run the baseline regression controlling for vertical integration using a dummy which takes value 1 if the firm's main sic code is Retail (SIC 52), but some of its establishments (local units) are classified in Wholesale (SIC 51), or if the firm belongs to a larger enterprise group which owns other firms whose main SIC code is Wholesale $^{31}$. The coefficient on the vertical integration variable is positive and significant, but so are the coefficients on our size variables, which remain virtually unchanged. Second, in columns 5 and 6 we explore the idea that the complementarity between larger stores and vertical integration might drive our main result, but we do not find support for this hypothesis. Finally, we entered transport costs (ln_T) separately to input costs. This is to test whether the small shops effect is just a reflection of the notion that serving more small stores involves more transport and, to the extent, that there might be congestion involved, lower productivity. In the data, the fraction of transport costs are positively correlated with the fraction of small stores, but the regression table shows that the coefficient on small stores is hardly altered.

In a final check we tried an IV type approach to the basic specification of Table 4, column 3, i.e. fixed effects with log median size, where we used initial median size as an instrument for subsequent median size (since we control for fixed effects, this effectively uses initial median size as an instrument for subsequent changes in median size, where initial median size is measured as the median size of the shops within the chain in the first period the chain is observed and the sample is all observations excluding the first period the chain is observed). The rationale behind the instrument is that the response to the exogenous change in planning regulation (which raised the cost of opening larger shops) might have differed according to the stores distribution that firms had in the pre-regulatory environment. For example, firms with initially larger stores might have faced higher adjustment costs in changing stores' distribution (i.e. opening smaller stores) in subsequent periods. This is consistent with the evidence that "big-box" retailers such as ASDA/WalMart had significant problems in adjusting their store strategies to the new planning regime after the 1996 reform (Competition Commission, 2000, Griffith and Harmgart, 2005). An immediate test is whether the instrument is correlated with subsequent changes in median store sizes i.e. the first stage F test prescribed by Stock and Staiger (1998). The coefficient is -0.0006 (significant at the $1 \%$ level), suggesting that, indeed, firms with larger stores in the initial period experienced smaller

\footnotetext{
${ }^{30}$ See Holmes (2002) for a model where vertical integration and large stores arise as optimal complementary choices with the introduction of IT.

${ }^{31}$ The results are robust if we use only the first part of the definition, i.e. a firm is vertically integrated if its main SIC code is Retail (SIC 52) but some of its establishments are classified in Wholesale (SIC 51).
} 
changes in stores size. The F statistic in the first stage regression if 36, which is well beyond the Stock and Yogo threshold of $16 .^{32}$

The sample generated from this exercise was 2,353 firms, which yielded an LSDV coefficient of $0.013(\mathrm{se}=0.014)$ on log median size. The IV result was $0.144(\mathrm{se}=0.06)$, both larger than the OLS and more precisely estimated. Thus the IV estimate is much large than this or the OLS or LSDV estimates in Table 3, 4 and 5. What is the interpretation of the higher IV coefficient relative to the OLS/LSDV coefficient? Discounting the bias from weak instruments, it could be first that IV is upward biased due to a correlation between the instrument and unobservables that was exacerbated by using IV relative to OLS/LSDV. To explain the higher upward bias relative to OLS it would have to be that initial size has a higher correlation with omitted factors affecting changes in productivity and median store size than the OLS/LSDV bias due to the correlation between omitted factors affecting productivity and median store size. A second possibility is that IV is unbiased, but OLS/LSDV is downward biased due to endogeneity, due to a negative correlation between omitted factors causing chain productivity and median store size. Here it would have to be that better managers chose to open smaller stores, which seems the reverse of what is usually argued. Third, OLS/LSDV might be downward biased due to measurement error in the changes in median store size that is corrected by instrumenting with initial store size. It is quite likely that within-firm employment is misreported, although without explicit checking of the data against published records (which we cannot do due to confidentiality), the extent of this is hard to know. We do however know that changes in mismeasured variables amplify the measurement error bias and hence the initial level of median store size might be a better variable for this reason. Finally, it is possible that there are heterogeneous coefficients and that IV has identified the local marginal effect arising from initially big firms, for whom there might have been a very severe penalty to becoming small. For all these reasons, our OLS results may be an understatements of the causal effects of the move to smaller within-chain store sizes due to regulation.

Finally, as mentioned above, we do not have data on IT (separately from other K terms). It is quite possible that the mix of store sizes in $\phi$ is correlated with IT, where more IT is needed to co-

\footnotetext{
32 The instrument might however be invalid if it is correlated with any unobservables that affect also affect changes in productivity and changes in store sizes. Thus suppose for example, that chains with initially high median store sizes have unobservably better management throughout the period. If better managers affect both subsequent productivity growth (not levels) and changing store sizes then the instrument might be capturing this effect and not a causal link between changing store sizes and productivity growth. One possibility is that there is no relation between initial management and subsequent changes since management itself might change. Otherwise predicting the relation between initial management and subsequent changes is not clear; better managers might be good or bad change managers for example.
} 
ordinate more large and small stores. In this case, were we to measure IT at store level (these data are not collected by the ONS) then there would be no effect on TFP and the measured slowdown would be illusory. However, much recent work on IT and productivity suggests IT alone is not sufficient to account for productivity, rather complementary organisational structures are required (see e.g. Bresnahan, Brynjolfsson and Hitt, 2000). To the extent that store sizes controls for such complementarity organisational structure, then size would affect TFP even with IT data.

\subsection{Economic significance of results}

We believe there is some support for a statistically significant association between productivity and various measures of the presence of small shops in a chain of stores. To judge the economic significance of this we proceed in Table 7 to consider the effect of changes in median employment.

The columns in Table 7 show the results for the four industries named in row 1 and for the total sectors, where the total sector results are the employment-weighted numbers using the employment weights in row 2. Row 3 shows TFP growth for each firm by using the change in log output less the cost-share weighted change in log input, ${ }^{33}$ weighted the fraction of employment in the firm in the relevant SIC for each year. The figures in row 3 are the sums of this for each SIC and the total column the weighted sum (of each number in row 3, weighted by the industry employment shares in row 2). ${ }^{34}$ Row 3 shows TFP growth rates of $-0.28 \%$ pa in supermarkets, $0.10 \%$ pa in food, $0.56 \%$ pa in pharmaceutical and $0.84 \%$ pa in the rest. The overall productivity growth rate for retailing is, on our sample, $0.07 \%$.

Before passing to other calculations, how do these data compare with other TFP estimates? First, these are TFP calculated from gross output, which is always lower than that calculated from value added (Domar, 1963). Basu et al (2003) report UK gross output industry level TFP growth rates, $1995-2000$ for retail trade, of $-0.58 \%$ (Table 5 , note $+3.23 \%$ for the US). For $1995-2002$, $+0.24 \%$ in Timmer and Inklaar (2005, Table 6, note $0.41 \%$ for the US). Second, our growth rates are calculated for our sample of chains and thus omit small shops (as we show below however, chains account for $96 \%$ of value added in retailing). Third, the chains in the sample had to survive at least two periods to be included in the sample. Thus it misses, to some extent, the industry

\footnotetext{
${ }^{33}$ The factor cost shares were for employment the share of gross output accounted for by labour costs, for materials the share accounted for by purchases of materials and for capital the remaining share. An alternative is to use the implied output elasticities from the regressions instead of the factor cost shares. In the light of the possible biases to the elasticities we used the actual factor cost shares which also eases comparison with aggregate figures.

${ }^{34}$ Strictly speaking the TFP growth rates should be Domar weighted but we ignore this here: there are few sales by each retailer to the other and employment is somewhat better measured than output.
} 
productivity gains from entry and exit of new firms and so might be expected to be below the industry data. Note finally that it is of interest that the sector with the fall in the median store size has had the lowest TFP growth.

Returning to Table 7, row 4 shows the coefficient on log median employment size from the earlier regression. Rows 5 and 6 show the median employment in each industry for our sample in 1997/8 and 2002/3. As we saw in Table 3 above (for the full sample) in the regression sample median employment has fallen in "Supermarkets" and risen slightly elsewhere. The seventh row shows the predicted effect from the actual change times the coefficient. In supermarkets, the predicted effect is to lower annual $\triangle \ln T F P$ by $0.64 \%$ per year. In SIC524 and "Rest (524)" the effect is to raise it by $0.55 \%$ per year and the effect is small and negative in SIC522 (due to the negative coefficient in Table 5).

The final two rows set out two counterfactuals. Row 8 imagines there was no reduction in median store size in supermarkets (but other sectors were unaffected). Given the supermarkets are so much larger than other industries, this seems to be the counter-factual of immediate interest, since it is likely that only for supermarkets would store size regulation be binding, but for completeness, row 9 shows no change in any median store size in all industries. Comparing rows 8 and 9 with the actual case in row 2, in row 8, TFP growth is raised in supermarkets (by the amount in row 7) and unaffected elsewhere and in row 9 it is raised in supermarkets, but slightly lowered elsewhere. At the same employment weights, the overall effect is to raise overall TFP growth from $0.07 \%$ pa to $0.44 \%$ pa and $0.27 \%$ pa.

The following points are worth noting. First, in the second scenario, even though productivity growth falls for the non-supermarket sectors, supermarkets are large enough that overall productivity growth still rises. Note however, that because median store sizes rose in "Pharmaceuticals" and "Rest" keeping median store sizes at their initial level lowers TFP growth in these sector in the second counterfactual case, where median store sizes do not change in any industry.

Second, what might this tell us about the effect of planning regulations in UK retailing productivity growth? The Basu et al (2003) data shows UK retail trade gross output productivity growth slowing from $0.38 \%$ pa $1990-95$ to $-0.58 \%$ pa $1995-2000$, a slowdown of 0.96 percentage points per annum (pppa). Let us assume, for the purposes of this illustrative calculation, that planning has caused a move to small stores and we have indentified the causal effects of planning on store sizes. Our results suggest that in the absence of changes in store sizes in supermarkets only productivity growth would have been $0.44 \%$ pa rather than the actual $0.07 \%$ pa (see the total 
columns in row 3 and row 9). Thus we estimate an implied slowdown due to changes in store sizes of (0.27-0.07)=0.37 pppa. This is about 39\% (0.37/0.96) of the Basu et al slowdown. ${ }^{35}$ Note too (Basu et al, footnote 15) that UK retailing by itself accounts for $1 / 3^{\text {rd }}$ of the UK (private sector) economy-wide TFP deceleration. Thus we estimate that regulation in retailing accounts for $13 \%$ $\left(1 / 3^{\text {rd }}\right.$ of $\left.39 \%\right)$ of the economy-wide deceleration.

Finally, it is important to note that this is an effect on measured productivity and not welfare. So, for example, it is perfectly possible that consumers are happy to pay for such changes due to increased convenience and the like.

\subsection{The cost of regulation}

The above data suggest the TFP slowdown is associated with retail chains moving toward small store formats. It could of course be that consumers value small stores. Hence a calculation of interest is to work out the implied cost sacrifice (due to reduced TFP) per small shop that has been created. Our discussion above suggested that regulation was likely most binding on the nonspecialised (supermarket) sector, so we shall calculate the implied regulation effect for this sector.

Our regressions suggest that the movement to smaller median stores has slowed TFP growth by $0.64 \%$ pa in supermarkets (i.e. the difference between actual TFP growth and what TFP growth would have been with no move to smaller stores, row 9 less row 3 in Table 7. Thus one way of thinking about the counter-factual situation where there is no regulation is as follows. Total value added in supermarkets was $£ 20,790 \mathrm{bn}$, with chains accounting for $99 \%$ of it. Thus in the counterfactual situations, had there been no TFP slowdown, chains would have been able to produce $£ 132 \mathrm{~m}$ more per year (£20bn*0.99*0.64\%).

We can express this foregone production in terms of the additional small chain stores created during the time period under consideration. In 1997/8 there were 1,359 small stores affiliated to national supermarket chains and in 2002/3, 2,859. This corresponds to a rise in 1,500 small chain stores. ${ }^{36}$ Therefore, the extra cost associated with each new small chain store has been $£ 132 \mathrm{~m} / 1,500=£ 88,000$ per store. There are a number of points worth making regarding these

\footnotetext{
${ }^{35}$ Another way to think of our data is relative to the US, although the counter-factual is not as clear without knowing what happened in the US to store sizes for large chains in supermarkets. The Basu et al and Timmer and Inklaar suggests that US retail TFP growth is about 7 times and 2 times respectively that in the UK. Our data here suggests that were there to be have been no change in median shop sizes, UK TFP growth would have been about 3 times greater. This then overexplains the Timmer/Inklaar figures, but is about $40 \%$ of the Basu at all figures.

${ }^{36}$ Table 1 shows in base period, 14,853 shops in SIC521, from table 2, 15\% of those shops were in large chains, which is 2, 228 stores. From Table 3, 61\% of these shops were below the median size of large chain stores in the base period, which is 1,359. By 2002/3 there were 2,859 small stores within national supermarket chains (using the analogous tables, this is from 18,552 total shops, of which $23 \%$ in large chains, of which $67 \%$ are small).
} 
calculations. First, the counterfactual assumes that extra output is "freely" available, that is, that any extra output requires no inputs to produce it. In this context, this may not be too bad an assumption, since one way of thinking about the TFP here is the organisational capital in running large stores. If this is already existing in current large stores and can be applied to those stores that would have been large in the counterfactual then the assumption it is freely available would hold. Second, the counterfactual benefit above assumes that the current amount of GDP could have been produced at lower cost by $0.64 \%$, thus raising potential returns to workers and capital at given prices. If markets are competitive then prices will fall raising consumer surplus by this amount but also by the Harberger triangle, suggesting this is an understatement of the welfare loss (we would need a complete model of consumer demand in big and small store to undertake a full welfare calculation).

How does this work relate to Griffith and Harmgart (2008)?. First, they set out a model predicting the probability of a more or less monopolised market structure, crucially, taking account of individual preferences (e.g. for convenience stores). Second, they estimate a model predicting the probability of having zero, one, two etc. stores in a market, separately for large and small stores, see their table 6. They find that (p.23), controlling for other effects, if more planning applications had been approved, the resulting market equilibrium would have had more stores, with their strongest (in significance) marginal effects resulting in more large stores (see table 6, column 2 and table 7 , column 1 and 2 .

Third, they estimate a model linking the price at supermarkets with the local market presence of single supermarket, duopoly etc). They then simulate the effect on prices of a relaxation in planning regulations via the increase in the probability of a local consumer facing more supermarkets in the area. They find that (p.24) prices would have been lower by about $0.03 \%$ of weekly spend (table 17 , last row) which is $£ 12 \mathrm{~m}$ per year.

How does these findings compare to ours, in particular our supply side calculations of a loss of economies of scale/scope of $£ 132 \mathrm{~m}$ ? First, the counter-factual that we estimate is very different. We estimate a return to the 1997/8 size profile of stores. They estimate a change in market structure due to lifting of all planning regulations. Their results suggest there would have been more large stores, so the counterfactuals are related, but not the same. (It is worth noting that they find a positive relation between denying planning applications and the probability of having local market structures with fewer large stores, see their table 2, they also find a (statistically insignificant) relation between denying planning applications and the probability of having local market structures with more small stores; so this latter finding is in line with the shift to more small 
stores that we are postulating, although on our data we are unable to make any statements about the local markets where this effect might be concentrated).

Second, as mentioned above, their raw data shows an increase in openings of small supermarket stores after regulation (see their figure 1). But our number is for a trend towards smaller stores, which we assert is correlated with changes in regulation. If part of that trend simply reflects changes in e.g. demand for convenience stores, which Griffith and Harmgart control for, then we have overstated the effects of regulation on the trend to smaller stores relative to them.

Third, the mechanism by which planning affects real outcomes is very different in these studies. The Griffith/Harmgart effect comes about from changes in price-setting from less competition due to the restricted entry of (statistically the most important effect) large stores. Our effect comes from changes in supply due to the shift to small stores. Since our data are on revenues, our effect is from changes in both prices and quantities following the shift to smaller stores, which could be larger than the shift to prices. Finally, we might have correctly estimated the changes in costs, but due to incomplete pass-though this is of course perfectly consistent with a smaller change in prices. ${ }^{37}$

\section{Conclusion}

We have used UK micro data to explore whether tightened regulation might have been associated with the reduction in UK retailing productivity growth 1997-2003. We document a shift to smaller shops following a regulatory change in 1996. This might have caused a slowdown in productivity growth if firms (a) lose scale advantages, by moving to smaller stores and (b) lose scope advantages if existing organisational resources appropriate to larger stores are not perfectly substitutable with the organisational capital required to run smaller stores. Our micro data shows a positive relation between firm-level TFP for multi-store chains and large store formats, using various measures of the sizes and the size distribution of the stores within the chain. Our results suggest the fall in shop sizes is associated with lowered TFP growth by about $0.4 \%$ pa, about $40 \%$ of the post- 1995 slowdown in UK retail TFP growth. Given that the slowdown in retailing alone is about $1 / 3^{\text {rd }}$ of the entire slowdown in UK market sector TFP growth, this is about $13 \%$ of that entire market sector slowdown. It is also around £88,000 per small chain store created.

\footnotetext{
${ }^{37}$ The degree of pass-through depends critically on assumptions about demand e.g. for straight line demand curves it is 50\%, but could be any number, see Bulow and Pfleiderer (1983).
} 
We believe our results suggest a robust correlation between average store size and retailers' measured productivity. In future work it might be interesting to pursue a number of other avenues. First, measured productivity reflects a number of different effects such as assortment, convenience etc. for which consumers might be quite happy to pay. Second, we have postulated a link between changes in regulation and store size: this the subject of another paper, Sadun (2008), but more exploration of this is clearly needed. Third, it would be of interest to explore other countries. Finally, more data would help us better understand the reason for this correlation. As we have indicated simple explanation might be that the correlation is generated by pure economies of scale at the store level. A more complex channel involves complementarities between store size, shared information across stores and other inputs for example, IT investments. Without store level IT data, answering this final question may be better suited to private data sets. 


\section{References}

\section{References}

Aguirregabiria, V., Mira P., and Roman H. (2007), “An Estimable Dynamic Model of Entry, Exit and Growth in Oligopoly Retail Markets," Forthcoming in the American Economic Review. Papers and Proceedings. May, 2007

Basker, E., Klimek, S., Hoang Van, P., (2007), "Supersize it: the Growth of Retail Chains and the Rise of the Big Box Retail format”, mimeo

Basu, S., Fernald, J.G., Oulton, N., Srinivasan, S. (2004). 'The case of the missing productivity growth, or does information technology explain why productivity accelerated in the United States but not in the United Kingdom?', in Gertler, M., Rogoff, K. (Eds.), NBER Macroeconomics Annual 2003, Cambridge, MA: The MIT Press. Data appendix: http://www.nber.org/data-appendix/basu_et_al/basu-et-al9-22-03_u.k.data-appendix.pdf

Beresteanu, A. and Ellickson, P., “The Dynamics of Retail Oligopoly”, (2006), mimeo.

Betancourt, R, (2004), “The Economics of Retailing and Distribution“, Edward Elgar Publishing, Ltd. November 2004

Bloom, N., Sadun, R. and Van Reenen, J., “It ain't what you do, it’s the way you do IT”, (2007), mimeo London School of Economics.

Bond, S and Soderbom, M., (2005), “Adjustment costs and the identification of Cobb Douglas production functions”, 30 pp., IFS Working Papers, W05/04.

Bond, S., and Van Reenen, J., (2003) "Microeconometric Models of Investment and Employment" , Forthcoming, Handbook of Econometrics, Volume 6.

Betancourt, R., and Gautschi, D., (2001) "Product Innovation in Services: A Framework for Analysis", in M. Baye and J. Nelson (eds.), Advertising and Differentiated Products, Volume 10 in Advances in Applied Economics, JAI Press, available at http://www.bsos.umd.edu/econ/betancourt/distribution/distribution.htm as http://www.bsos.umd.edu/econ/betancourt/distribution/scvrjai.s01.pdf

Betancourt, R. and D. Gautschi (1993) , "The outputs of retail activities: concepts, measurement and evidence from U.S. census data”, The Review of Economics and Statistics, 75(May), pp.294-301

Bulow, J and P. Klemperer (1983), “A Note on the Effect of Cost Changes on Prices”, The Journal of Political Economy, Vol. 91, No. 1 (Feb., 1983), pp. 182-185.

Criscuolo C., Haskel J. and Martin R., (2003). 'Building the evidence base for productivity policy using business data linking', Economic Trends 600 November 2003, 39-51, available at ww.statistics.gov.uk/articles/economic_trends/ETNov03Haskel.pdf.

Griffith R, and H. Harmgart, (2005) "Retail productivity," IFS Working Papers W05/07, Institute for Fiscal Studies. 
Griffith, R., and Harmgart, H (2008), "Supermarkets and Planning Regulation," CEPR Discussion Papers 6713, C.E.P.R. Discussion Papers.

Haskel, J., Jarmin, R., Motohashi, K., Sadun, R., (2007), "Retail Market Structure and Dynamics: A Three Country Comparison of Japan, the U.K. and the U.S.”, mimeo.

Holmes, T. J. "Bar Codes Lead to Frequent Deliveries and Superstores." RAND Journal of Economics, Winter 2001, 34(4), pp. 708-725.

Jarmin, R., Klimek, S., and Miranda, J., (2005), "The Role of Retail Chains: National, Regional, and Industry Results," Working Papers 05-30, Center for Economic Studies, U.S. Census Bureau.

Martin, R., (2004), “Building the UK Capital Stock”, CeRiBA mimeo.

McGuckin, R.H., M. Spiegelman and B. van Ark (2005), “The Retail Revolution. Can Europe Match U.S. Productivity Performance?, Perspectives on a Global Economy”, Research Report R1358-05-RR, The Conference Board, New York

McKinsey Global Institute, Driving Productivity in the UK Economy (October 1998). http://www.mckinsey.com/mgi/reports/pdfs/ukprod/Food_retail.pdf

Oi, W. (1992), "Productivity in the Distributive Trades: The Shopper and the Economies of Massed Reserves”, in Z. Griliches, ed., Output Measurement in the Service Sectors, University of Chicago Press.

Sadun, R., (2008) “Does Planning Regulation protect independent retailers?”, CEP Working Paper N.888, August

Timmer, Marcel \& Inklaar , Robert, 2005. "Productivity differentials in the U.S. and EU distributive trade sector: statistical myth or reality," GGDC Research Memorandum 200576, Groningen Growth and Development Centre, University of Groningen\#

Triplett, J. and B. Bosworth. (2004), Productivity in the U.S. Services Sector. New Sources of Economic Growth, The Brookings Institution, Washington D.C. 
TABLE 1. SUMMARY STATISTICS BY THREE-DIGIT INSUSTRY

\begin{tabular}{lcccccc}
\hline \multirow{2}{*}{ sic3 } & \multicolumn{1}{c}{ Total employment } & \multicolumn{2}{c}{ Stores } & \multicolumn{2}{c}{ Cr 15 } \\
& $\mathbf{1 9 9 7 / 1 9 9 8}$ & $\mathbf{2 0 0 2 / 2 0 0 3}$ & $\mathbf{1 9 9 7 / 1 9 9 8}$ & $\mathbf{2 0 0 2 / 2 0 0 3}$ & $\mathbf{1 9 9 7 / 1 9 9 8}$ & $\mathbf{2 0 0 2 / 2 0 0 3}$ \\
\hline 521 Supermarkets & 876,905 & $1,100,000$ & 14,853 & 18,552 & $43.2 \%$ & $45.0 \%$ \\
522 Food, Bev, Tob & 94,692 & 78,763 & 13,266 & 10,957 & $2.9 \%$ & $2.0 \%$ \\
523 Pharmaceutical & 70,483 & 65,324 & 6,975 & 7,031 & $3.2 \%$ & $2.4 \%$ \\
524 Other & 521,455 & 705,689 & 48,455 & 53,369 & $10.5 \%$ & $13.2 \%$ \\
525 Second-hand & 2,917 & 3,878 & 819 & 1,469 & $0.1 \%$ & $0.1 \%$ \\
526 Not in store & 49,016 & 43,838 & 1,100 & 835 & $2.5 \%$ & $1.8 \%$ \\
527 Repair & 4,340 & 6,691 & 953 & 958 & $0.2 \%$ & $0.3 \%$ \\
\hline
\end{tabular}

Source: Authors' calculations from ARD.

Notes: full descriptions of SICs are as follows:

SIC Industry

521 Retail sales in non-spec covering e.g. food, Includes supermarkets and department stores

beverages or tobacco

522 Food, beverages, tobacco in specialised

stores

523 Pharm and medical goods, cosmetic and Includes chemists

toilet articles

524 Other retail sales of new goods in Includes sales of textiles, clothing, shoes, furniture, elect appliances, hardware, books, specialised stores

525 Second-hand

526 Not in stores newspapers and stationary, cameras, office supplies, computers. Clothing is biggest area Mostly second-hand books, second-hand goods and antiques

Mostly mail order and stalls and markets

527 Repair

Repair of personal goods, boots and shoes, watches and clocks 
TABLE 2. SHARE OF EMPLOYMENT IN STAND ALONE STORES, SMALL AND LARGE CHAINS

\begin{tabular}{|c|c|c|c|c|c|c|c|c|c|c|c|c|}
\hline & \multicolumn{6}{|c|}{ Employment Shares } & \multicolumn{6}{|c|}{ Store Shares } \\
\hline & \multirow{2}{*}{\multicolumn{2}{|c|}{$\begin{array}{l}\text { Stand Alone Shops } \\
1997 / 1998 \quad 2002 / 2003\end{array}$}} & \multicolumn{2}{|c|}{ Small Chains } & \multicolumn{2}{|c|}{ Large Chains } & \multicolumn{2}{|c|}{ Stand Alone Shops } & \multicolumn{2}{|c|}{ Small Chains } & \multicolumn{2}{|c|}{ Large Chains } \\
\hline & & & $1997 / 1998$ & $2002 / 2003$ & $1997 / 1998$ & $2002 / 2003$ & $1997 / 1998$ & $2002 / 2003$ & $1997 / 1998$ & $2002 / 2003$ & $1997 / 1998$ & $2002 / 2003$ \\
\hline Supermarkets & 0.14 & 0.12 & 0.23 & 0.18 & 0.63 & 0.70 & 0.72 & 0.66 & 0.13 & 0.11 & 0.15 & 0.23 \\
\hline Food, Bev, Tob & 0.62 & 0.60 & 0.28 & 0.29 & 0.11 & 0.11 & 0.79 & 0.76 & 0.15 & 0.16 & 0.06 & 0.07 \\
\hline Pharmaceutical & 0.33 & 0.31 & 0.24 & 0.24 & 0.43 & 0.45 & 0.47 & 0.44 & 0.27 & 0.26 & 0.26 & 0.30 \\
\hline Other & 0.36 & 0.33 & 0.25 & 0.21 & 0.40 & 0.46 & 0.61 & 0.62 & 0.22 & 0.18 & 0.18 & 0.20 \\
\hline Second-hand & 0.85 & 0.79 & 0.08 & 0.10 & 0.14 & 0.11 & 0.88 & 0.79 & 0.06 & 0.09 & 0.12 & 0.12 \\
\hline Not in store & 0.42 & 0.50 & 0.47 & 0.30 & 0.11 & 0.20 & 0.89 & 0.94 & 0.08 & 0.04 & 0.03 & 0.02 \\
\hline Repair & 0.74 & 0.75 & 0.16 & 0.10 & 0.09 & 0.16 & 0.80 & 0.87 & 0.08 & 0.04 & 0.12 & 0.09 \\
\hline
\end{tabular}

Notes: Stand-alone are single stores. Small Chains are shops in a frim operating in multiple regions, but not all 11 regions, , Large Chains are shops in fiirms in all 11 regions..

Source: Authors' calculations from ARD. 
TABLE 3. SIZE DISTRIBUTION OF EMPLOYMENT WITHIN SMALL AND LARGE CHAINS

\begin{tabular}{|c|c|c|c|c|c|c|c|c|c|c|c|c|c|}
\hline \multirow[t]{2}{*}{ Small Chains } & & \multicolumn{2}{|c|}{ Standard Deviation } & \multicolumn{2}{|c|}{ Percentage Small (emp } & \multicolumn{2}{|c|}{ Percentage Small } & \multicolumn{2}{|c|}{ P25 } & \multicolumn{2}{|c|}{ p50 } & \multicolumn{2}{|c|}{ P75 } \\
\hline & & $1997 / 1998$ & $2002 / 2003$ & $1997 / 1998$ & $2002 / 2003$ & $1997 / 1998$ & $2002 / 2003$ & $1997 / 1998$ & $2002 / 2003$ & $1997 / 1998$ & $2002 / 2003$ & 1997/1998 & $2002 / 2003$ \\
\hline & 521 & 25.22 & 29.27 & 0.40 & 0.39 & 0.59 & 0.53 & 12.17 & 14.98 & 25.22 & 29.27 & 64.29 & 64.07 \\
\hline & 522 & 6.28 & 6.75 & 0.43 & 0.40 & 0.61 & 0.55 & 3.82 & 4.25 & 6.28 & 6.75 & 12.38 & 11.75 \\
\hline & 524 & 6.46 & 7.54 & 0.44 & 0.40 & 0.61 & 0.55 & 3.89 & 4.43 & 6.46 & 7.54 & 11.98 & 14.02 \\
\hline & 528 & 9.47 & 9.20 & 0.48 & 0.45 & 0.63 & 0.58 & 4.81 & 5.28 & 9.47 & 9.20 & 27.01 & 21.08 \\
\hline \multirow[t]{6}{*}{ Large Chains } & & \multicolumn{2}{|c|}{ Standard Deviation } & \multicolumn{2}{|c|}{ Percentage Small (emp } & \multicolumn{2}{|c|}{ Percentage Small } & \multicolumn{2}{|c|}{ P25 } & \multicolumn{2}{|c|}{ p50 } & \multicolumn{2}{|c|}{ P75 } \\
\hline & & $1997 / 1998$ & $2002 / 2003$ & $1997 / 1998$ & $2002 / 2003$ & $1997 / 1998$ & $2002 / 2003$ & $1997 / 1998$ & $2002 / 2003$ & $1997 / 1998$ & $2002 / 2003$ & $1997 / 1998$ & $2002 / 2003$ \\
\hline & 521 & 72.45 & 56.82 & 0.43 & 0.51 & 0.61 & 0.67 & 31.14 & 22.51 & 72.45 & 56.82 & 140.52 & 117.52 \\
\hline & 522 & 6.09 & 5.93 & 0.52 & 0.41 & 0.65 & 0.54 & 3.94 & 3.94 & 6.09 & 5.93 & 8.77 & 9.04 \\
\hline & 524 & 11.58 & 13.44 & 0.37 & 0.30 & 0.57 & 0.47 & 6.72 & 7.54 & 11.58 & 13.44 & 23.22 & 29.36 \\
\hline & 528 & 8.83 & 8.58 & 0.37 & 0.35 & 0.60 & 0.52 & 4.85 & 4.96 & 8.83 & 8.58 & 27.04 & 19.50 \\
\hline
\end{tabular}

Notes: Data for Chains. Small Chains are shops in a firm operating in multiple regions, but not all 11 regions, , Large Chains are shops in firms in all 11 regions.

Source: Authors' calculations from ARD 
TABLE 4. PRODUCTIVITY AND RETAIL STORES DISTRIBUTION

\begin{tabular}{|c|c|c|c|c|c|c|c|c|c|}
\hline & (1) & (2) & (3) & (4) & (5) & (6) & (7) & (8) & (9) \\
\hline Dependent Variable & $\ln (\mathrm{GO})$ & $\ln (\mathrm{GO})$ & $\ln (\mathrm{GO})$ & $\ln (\mathrm{GO})$ & $\ln (G O)$ & $\ln (\mathrm{GO})$ & $\ln (\mathrm{GO})$ & $\ln (\mathrm{GO})$ & $\ln (G O)$ \\
\hline Fixed effects & NO & YES & YES & YES & YES & YES & YES & YES & YES \\
\hline $\begin{array}{l}\text { ln_N } \\
\text { Ln(Employment) }\end{array}$ & $\begin{array}{c}0.2279 * * * \\
(0.0101)\end{array}$ & $\begin{array}{c}0.2793 * * * \\
(0.0278)\end{array}$ & $\begin{array}{c}0.2770 * * * \\
(0.0278)\end{array}$ & $\begin{array}{c}0.2746 * * * \\
(0.0274)\end{array}$ & $\begin{array}{c}0.2749 * * * \\
(0.0274)\end{array}$ & $\begin{array}{c}0.2744 * * * \\
(0.0275)\end{array}$ & $\begin{array}{c}0.2744^{* * *} \\
(0.0275)\end{array}$ & $\begin{array}{c}0.2767 * * * \\
(0.0277)\end{array}$ & $\begin{array}{c}0.2900 * * * \\
(0.0286)\end{array}$ \\
\hline $\begin{array}{l}\text { In_K } \\
\ln (\text { Capital) }\end{array}$ & $\begin{array}{c}0.0955^{* * *} \\
(0.0082)\end{array}$ & $\begin{array}{c}0.0555 * * * \\
(0.0144)\end{array}$ & $\begin{array}{c}0.0535 * * * \\
(0.0144)\end{array}$ & $\begin{array}{c}0.0527 * * * \\
(0.0143)\end{array}$ & $\begin{array}{c}0.0530 * * * \\
(0.0143)\end{array}$ & $\begin{array}{c}0.0525 * * * \\
(0.0143)\end{array}$ & $\begin{array}{c}0.0524 * * * \\
(0.0143)\end{array}$ & $\begin{array}{c}0.0534^{* * *} \\
(0.0144)\end{array}$ & $\begin{array}{c}0.0520 * * * \\
(0.0147)\end{array}$ \\
\hline $\begin{array}{l}\text { ln_M } \\
\ln \text { (Materials) }\end{array}$ & $\begin{array}{c}0.6581 * * * \\
(0.0150)\end{array}$ & $\begin{array}{c}0.5024 * * * \\
(0.0405)\end{array}$ & $\begin{array}{c}0.5026^{* * * *} \\
(0.0405)\end{array}$ & $\begin{array}{c}0.5026 * * * \\
(0.0403)\end{array}$ & $\begin{array}{c}0.5023 * * * \\
(0.0403)\end{array}$ & $\begin{array}{c}0.5026 * * * \\
(0.0403)\end{array}$ & $\begin{array}{c}0.5025 * * * \\
(0.0403)\end{array}$ & $\begin{array}{c}0.5018 * * * \\
(0.0406)\end{array}$ & $\begin{array}{c}0.4883 * * * \\
(0.0410)\end{array}$ \\
\hline $\begin{array}{l}\text { Nat Chain } \\
\text { National Chain dummy }\end{array}$ & $\begin{array}{c}0.0030 \\
(0.0127)\end{array}$ & $\begin{array}{c}0.0727 * * * \\
(0.0252)\end{array}$ & $\begin{array}{c}0.0728 * * * \\
(0.0249)\end{array}$ & $\begin{array}{c}0.0708 * * * \\
(0.0248)\end{array}$ & $\begin{array}{c}0.0730 * * * \\
(0.0251)\end{array}$ & $\begin{array}{c}0.0710 * * * \\
(0.0247)\end{array}$ & $\begin{array}{c}0.0730 * * * \\
(0.0249)\end{array}$ & $\begin{array}{c}0.0744^{* * *} \\
(0.0252)\end{array}$ & $\begin{array}{c}0.0768 * * * \\
(0.0253)\end{array}$ \\
\hline $\begin{array}{l}\text { ln_m_emp } \\
\ln \text { (Stores median employment) }\end{array}$ & - & - & $\begin{array}{c}0.0261^{* * *} \\
(0.0095)\end{array}$ & - & - & $\begin{array}{c}0.0070 \\
(0.0106)\end{array}$ & $\begin{array}{c}0.0139 \\
(0.0098)\end{array}$ & $\begin{array}{c}0.0274 * * * \\
(0.0096)\end{array}$ & $\begin{array}{c}0.0357 * * * \\
(0.0123)\end{array}$ \\
\hline $\begin{array}{l}\text { Pct_emp_small } \\
\text { Percentage of employment in small stores }\end{array}$ & - & - & - & - & $\begin{array}{c}-0.0669 * * * \\
(0.0198)\end{array}$ & - & $\begin{array}{c}-0.0560 * * * \\
(0.0211)\end{array}$ & - & - \\
\hline $\begin{array}{l}\text { Pct_N_small } \\
\text { Percentage of small stores }\end{array}$ & - & - & - & $\begin{array}{c}-0.0712 * * * \\
(0.0193)\end{array}$ & - & $\begin{array}{c}-0.0641 * * * \\
(0.0223)\end{array}$ & - & - & - \\
\hline $\begin{array}{l}\text { In_iqr } \\
\text { In(Interquantile range) }\end{array}$ & - & - & - & - & - & - & - & - & $\begin{array}{c}0.0035 \\
(0.0058)\end{array}$ \\
\hline $\begin{array}{l}\text { coeff } \\
\text { Coefficient of variation }\end{array}$ & - & - & - & - & - & - & - & $\begin{array}{c}0.0086 \\
(0.0105)\end{array}$ & - \\
\hline Observations & 7469 & 7469 & 7469 & 7469 & 7469 & 7469 & 7469 & 7469 & 7088 \\
\hline R-squared & 0.99 & 1.00 & 1.00 & 1.00 & 1.00 & 1.00 & 1.00 & 1.00 & 1.00 \\
\hline
\end{tabular}

Notes: Robust standard errors in parentheses. * significant at $10 \%$; ** significant at $5 \%$; *** significant at $1 \%$. The time period is $1997-2003$. The dependent variable in all columns is the log of gross output. All columns include year dummies and controls for region, age, multinational and multi-group status. All columns except 1 include firm level fixed effects. Standard errors in brackets clustered at the reporting unit level to correct for heteroskedasticity of unknown form. A national chain is defined as a retail firm which operates stores in all 11 UK GOR regions. Pct_emp_small and Pct_N_small are defined, respectively, as the share of employment and the share of stores below firm level median employment in the first year the firm is observed. 
TABLE 5. INDUSTRY BREAKDOWN

\begin{tabular}{|c|c|c|c|c|}
\hline & (1) & (2) & (3) & (4) \\
\hline Dependent Variable & $\ln (\mathrm{GO})$ & $\ln (G O)$ & $\ln (G O)$ & $\ln (G O)$ \\
\hline Fixed effects & YES & YES & YES & YES \\
\hline Sector & 521 & 522 & 524 & Rest \\
\hline $\begin{array}{l}\text { ln_m_emp } \\
\text { In(Stores median employment) }\end{array}$ & $\begin{array}{c}0.0394 * * * \\
(0.0106)\end{array}$ & $\begin{array}{l}-0.0187 \\
(0.0320)\end{array}$ & $\begin{array}{c}0.0379 * * * \\
(0.0142)\end{array}$ & $\begin{array}{c}0.0022 \\
(0.0156)\end{array}$ \\
\hline $\begin{array}{l}\text { Pct_emp_small } \\
\text { Percentage of employment in small stores }\end{array}$ & $\begin{array}{l}-0.0355 \\
(0.0252)\end{array}$ & $\begin{array}{l}-0.0496 \\
(0.0520)\end{array}$ & $\begin{array}{c}-0.0654 * * * \\
(0.0232)\end{array}$ & $\begin{array}{l}-0.0258 \\
(0.0438)\end{array}$ \\
\hline $\begin{array}{l}\text { Pct_N_small } \\
\text { Percentage of small stores }\end{array}$ & $\begin{array}{c}0.0189 \\
(0.0259)\end{array}$ & $\begin{array}{l}-0.0876 \\
(0.0649)\end{array}$ & $\begin{array}{l}-0.0623 * * \\
(0.0298)\end{array}$ & $\begin{array}{l}-0.0623 \\
(0.0491)\end{array}$ \\
\hline $\begin{array}{l}\text { Observations } \\
\text { R-squared }\end{array}$ & 1109 & $\begin{array}{l}998 \\
100\end{array}$ & 4292 & 1070 \\
\hline
\end{tabular}

Notes: Robust standard errors in parentheses. * significant at $10 \%$; ** significant at $5 \%$; *** significant at $1 \%$. The time period is 1997-2003. Each line corresponds to a different regressionThe dependent variable in all columns is the log of gross output. All columns include year dummies and controls for capital, employment, materials, region, age, multinational and multi group status. All columns include firm level fixed effects. Standard errors in brackets clustered at the reporting unit level to correct for heteroskedasticity of unknown form. A national chain is defined as a retail firm which operates stores in all 11 UK GOR regions. Pct_emp_small and Pct_N_small are defined, respectively, as the share of employment and the share of stores below firm level median employment in the first year the firm is observed. 
TABLE 6. ROBUSTNESS CHECKS

\begin{tabular}{|c|c|c|c|c|c|c|c|}
\hline & (1) & (2) & (3) & (4) & (5) & (6) & (7) \\
\hline Dependent Variable & $\ln (G O)$ & $\ln (G O)$ & $\ln (G O)$ & $\ln (G O)$ & $\ln (G O)$ & $\ln (G O)$ & $\ln (G O)$ \\
\hline Fixed effects & NO & YES & YES & YES & YES & YES & YES \\
\hline ln_N & $0.2770 * * *$ & $0.2746^{* * *}$ & $0.2763 * * *$ & $0.2765^{* * *}$ & $0.2737 * * *$ & $0.2737 * * *$ & $0.2324 * * *$ \\
\hline Ln(Employment) & $(0.0278)$ & $(0.0274)$ & $(0.0277)$ & $(0.0277)$ & $(0.0274)$ & $(0.0274)$ & $(0.0302)$ \\
\hline ln_K & $0.0535^{* * *}$ & $0.0527 * * *$ & $0.0532 * * *$ & $0.0534 * * *$ & $0.0523 * * *$ & $0.0522 * * *$ & $0.0624 * * *$ \\
\hline In(Capital) & $(0.0144)$ & $(0.0143)$ & $(0.0144)$ & $(0.0144)$ & $(0.0143)$ & $(0.0143)$ & $(0.0117)$ \\
\hline ln_M & $0.5026^{* * *}$ & $0.5026^{* * *}$ & $0.5022^{* * *}$ & $0.5021^{* * *}$ & $0.5021^{* * *}$ & $0.5019 * * *$ & $0.5865 * * *$ \\
\hline In(Materials) & $(0.0405)$ & $(0.0403)$ & $(0.0404)$ & $(0.0404)$ & $(0.0402)$ & $(0.0402)$ & $(0.0433)$ \\
\hline Nat Chain & $0.0728^{* * *}$ & $0.0708^{* * *}$ & $0.0726^{* * *}$ & $0.0721^{* * *}$ & $0.0705^{* * *}$ & $0.0709^{* * *}$ & 0.0295 \\
\hline National Chain dummy & $(0.0249)$ & $(0.0248)$ & $(0.0247)$ & $(0.0247)$ & $(0.0245)$ & $(0.0245)$ & $(0.0206)$ \\
\hline In_m_emp & $0.0261 * * *$ & - & $0.0263^{* * *}$ & $0.0280 * * *$ & - & - & - \\
\hline In(Stores median employment) & $(0.0095)$ & & $(0.0096)$ & $(0.0096)$ & & & \\
\hline Pct_N_small & - & $-0.0712 * * *$ & - & - & $-0.0731 * * *$ & $-0.0680 * * *$ & $-0.0573 * * *$ \\
\hline Percentage of small stores & & $(0.0193)$ & & & $(0.0194)$ & $(0.0204)$ & $(0.0222)$ \\
\hline Vt & - & - & $0.0213^{* *}$ & $0.0481 *$ & $0.0235^{* *}$ & $0.0382 *$ & - \\
\hline Vertical Integration Dummy & & & $(0.0106)$ & $(0.0288)$ & $(0.0106)$ & $(0.0222)$ & \\
\hline int_vt & - & - & - & - & - & -0.0283 & - \\
\hline Vertical Integration*In(Stores median employment) & & & & & & $(0.0345)$ & \\
\hline int_vt_m & - & - & - & -0.0107 & - & - & - \\
\hline Vertical Integration*In(Pct_n_small) & & & & $(0.0106)$ & & & \\
\hline ln_T & - & - & - & - & - & - & 0.0030 \\
\hline In(Transport costs) & & & & & & & $(0.0030)$ \\
\hline Observations & 7469 & 7469 & 7469 & 7469 & 7469 & 7469 & 5248 \\
\hline R-squared & 1.00 & 1.00 & 1.00 & 1.00 & 1.00 & 1.00 & 1.00 \\
\hline
\end{tabular}

Notes: Robust standard errors in parentheses. * significant at $10 \%$; ** significant at $5 \%$; *** significant at $1 \%$. The time period is $1997-2003$. The dependent variable in all columns is the log of gross output. All columns include year dummies and controls for region, age, multinational and multi-group status. All columns include firm level fixed effects. Standard errors in brackets clustered at the reporting unit level to correct for heteroskedasticity of unknown form. A national chain is defined as a retail firm which operates stores in all 11 UK GOR regions. Pct_emp_small and Pct_N_small are defined, respectively, as the share of employment and the share of stores below firm level median employment in the first year the firm is observed. The vertical integration dummy takes value 1 if the firm has establishments active in the Wholesailing sector. 


\begin{tabular}{|c|c|c|c|c|c|c|}
\hline \multicolumn{7}{|c|}{ TABLE 7. GROWTH ACCOUNTING } \\
\hline 1 & SIC & 521 & 522 & 524 & Rest & Total \\
\hline 2 & Industry weight & $58.17 \%$ & $3.25 \%$ & $33.19 \%$ & $5.38 \%$ & \\
\hline 3 & Weighted TFP growth & $-0.28 \%$ & $0.10 \%$ & $0.56 \%$ & $0.84 \%$ & $0.07 \%$ \\
\hline 4 & Co-eff on log median employ & 0.0394 & -0.0197 & 0.0379 & 0.0022 & \\
\hline 5 & Median employ, 1997/8 & 58.5 & 6.9 & 12.3 & 9.5 & \\
\hline 6 & Median employ, 2002/3 & 49.7 & 7.3 & 14.2 & 10.0 & \\
\hline 7 & Co-eff * change in median employ & $-0.64 \%$ & $-0.10 \%$ & $0.54 \%$ & $0.01 \%$ & \\
\hline \multicolumn{7}{|c|}{ Counterfactuals: } \\
\hline & TFP growth, no change in med emp in 521 & $0.36 \%$ & $0.10 \%$ & $0.56 \%$ & $0.84 \%$ & $0.44 \%$ \\
\hline & TFP growth, no change in med emp all inds & $0.36 \%$ & $0.20 \%$ & $0.02 \%$ & $0.83 \%$ & $0.27 \%$ \\
\hline
\end{tabular}

Notes to Table: Data are for SICs shown with total the employment weighted sum of the rows, using employment weights in Row 2. Row 4 is coefficient on median employment from Table 5. Growth rates are average annual growth rates between 1997 and 2003. Numbers in row 7 do not correspond exactly to row 4 *(row 6 - row 5 ) due to rounding in rows 5 and 6 . Rows 8 is row 3 less row 7 for SIC521 and row 3 otherwise, row 8 is row 3 less row 9. 


\section{Appendix 1: Further information on the UK planning regime}

The basis for planning dates more or less from the 1947 Town and Country Planning Act (1947). Any development of any land requires planning permission (there is much case law on what constitutes development). Minor developments (e.g. small changes to a house) are assumed to have been granted permission. Larger developments must ask for permission and decisions are based on whether the development fits with the applicable statutory development plan, a plan developed at local authority level. Such plans were developed by a series of local bodies often overlapping. A reform in 2004 decrees that the development plan for an area consists of a Regional Spatial Strategy, developed at the regional level (there are eight regions in England) and a "Local Development Framework" developed at local level but capable of being overruled by the Secretary of State. Both plans are supposed to be open to consultation and the RSS is supposed to set out development goals over the 15-20 year period. The Barker report suggests that an important aspect of local criteria is actually determined centrally since the Secretary of State issues Planning Policy Guidance Notes and Planning Policy Statements.

Applications for development are subject to consultation with interested parties e.g. between developers and local authorities. Pre-application discussions are common. If permission is refused then applications can be re-heard centrally. Large-scale applications e.g. new runways at airports if decided by the Secretary of State, are considered at a public inquiry.

Turning specifically to retail, the Barker Interim report paragraphs 5.27ff, describes the specific changes. In the 1980s out-of-town shopping locations was allowed relatively freely. In response to a perceived loss of in-town retail market share, the 1996 Planning Policy Guidance 6 was issued, stating the out-of-town centre locations should only be considered if town-centre or edge-of-centre locations had been ruled out. It is interesting to note that this change effected a remarkable reversal in the decline in town-centre retail development: in 1971 around 65\% of new floor space was constructed in town centres, falling to 23\% in 1996 and rising to over 40\% in 2003. This is shown in the diagram below38

\footnotetext{
${ }^{38}$ Whether this assisted the social goals of maintaining town centres is discussed in the Barker report. Retail presence is likely correlated with town centre wealth, but may not cause it, it may be the other way around. Pollution is lowered with out-of-centre shopping centres since a small fraction of private car journeys are actually for shopping and pollution from delivery lorries is increased in town centres.
} 


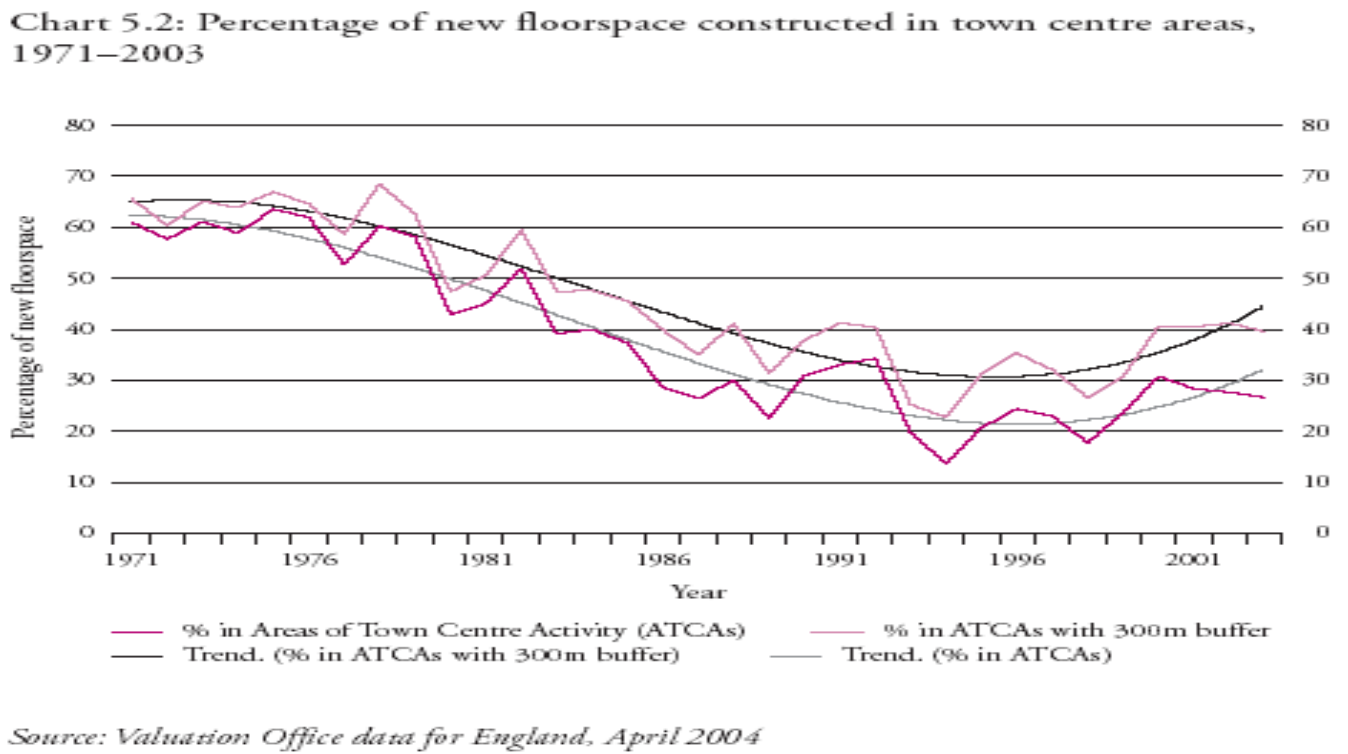

Source: Barker Interim Report.

In March 2005 there was a change to this framework (Planning Policy Statement 6). It is too early to assess its impact but it is potentially important with e.g. "a clear objective for local planning authorities to support efficient, competitive and innovative retail development - taking account of retail productivity; explicitly that larger stores may deliver benefits for consumers and that local planning authorities need to make provision where appropriate" (Barker Report para 5.47).

The interim Barker report contains an overview of UK planning and some detailed comments on retail planning (see the interim report link on http://www.hmtreasury.gov.uk/independent_reviews/barker_review_land_use_planning/barkerreview_land_use _planning_index.cfm

The interim report itself is at:

http://www.hm-treasury.gov.uk/media/65F/91/barker2_interim050706.pdf 
Appendix 2: Measuring retailing output and the relation between output and inputs39

We believe there are at least three broad questions here. First, what is the output of retailing that is of interest? Second, how does what is actually measured relate to what we might wish to measure? Third, how should we best judge how much the inputs have contributed to the output that we do measure?

The answer to the first question depends upon the research question, which here is typically as a first step to measuring productivity. This is usually then answered by the conceptual point that the right output concept when considering productivity of, say a shoe retailer is not the shoes it sells but the bundle of retailing services it offers surrounding the sales of the shoes. ${ }^{40}$ Such retail services are identified by Betancourt (2004, p.19ff) as ambience, product assortment, accessibility of location, assurance of delivery and information. If we had prices and quantities of these attributes then we could proceed, along with assumptions about the nature of competition. However, these services are typically not priced directly (e.g. shops do not charge for entry). So, this leads us to the second question of how to recover the value of such services from observable data which is typically on overall revenues and various input expenditures. We cannot answer this until we have a theory of how the various inputs and outputs in retailing are related, which is also needed to answer the third question of how the various measured inputs explain/account for the measured outputs.

Regarding this question we have two subquestions: first, what are relevant inputs and outputs; second what, if any, restrictions can we place on the relation between the various inputs and the inputs and outputs that might allow us to deduce some of the relevant properties (output elasticities for example) from different output measures? To fix ideas, consider a shoe seller, where the measured output is sales of shoes. What are the inputs? A partial list might be the following. First, the bought-in shoes themselves and second the shop (assuming it has a location). Third, the factors enabling a transaction to be made (staff to open the shop and take the money, cash tills, heating and lighting etc.) and fourth the bundle of distribution services surrounding the sale of shoes in the shop; the location of the shop, the ambience in the shop (e.g. the lighting, design, quality of the staff), the reputation of the shop for e.g. accepting returned goods etc. Let us denote this real bundle of services under the vector D. Define PQ as sales of goods at retail price $\mathrm{P}, \mathrm{P}_{\mathrm{W}} \mathrm{Q}_{\mathrm{W}}$ as the value of goods purchased for resale at the wholesale price $\mathrm{P}_{\mathrm{W}}$, other intermediate inputs used in retailing (lighting, electricity etc.) as $\mathrm{P}_{\mathrm{M}} \mathrm{M}$ and primary factors labour and capital as $P_{X} X$. Our data are typically values of sales, $P Q$, and values of expenditures on measured inputs, $\mathrm{P}_{\mathrm{W}} \mathrm{Q}_{\mathrm{W}}, \mathrm{P}_{\mathrm{M}} \mathrm{M}$ and $\mathrm{P}_{\mathrm{X}} \mathrm{X}$. Thus it is helpful in retailing to define three output measures: sales $=\mathrm{PQ}$, gross margins $\mathrm{P}_{\mathrm{GM}} \mathrm{Q}_{\mathrm{GM}}=\mathrm{PQ}-\mathrm{P}_{\mathrm{W}} \mathrm{Q}_{\mathrm{W}}$ and value added $\mathrm{P}_{\mathrm{V}} \mathrm{Q}_{\mathrm{V}}$ $=\mathrm{PQ}-\mathrm{P}_{\mathrm{W}} \mathrm{Q}_{\mathrm{W}}-\mathrm{P}_{\mathrm{M}} \mathrm{M}$. The most general form of a production function describing $\mathrm{Q}$ would be

$$
Q=A F\left(D, Q_{W}, M, X\right)
$$

where $\mathrm{A}$ is a shift parameter. An important question is what are the properties of $\mathrm{P}_{\mathrm{GM}} \mathrm{Q}_{\mathrm{GM}}=\mathrm{PQ}$ $\mathrm{P}_{\mathrm{W}} \mathrm{Q}_{\mathrm{W}}$, or more accurately, what are the marginal product properties from (3) observable from $\mathrm{P}_{\mathrm{GM}} \mathrm{Q}_{\mathrm{GM}}$ ? This question parallels the question in the production function literature on gross output versus value added, where the definition of value added is given, but the question of whether the properties of the gross output production function are recoverable from the value

\footnotetext{
39 This question is discussed in, for example, Betancourt (2002), Oi (1981) and Triplett and Bosworth (2003).

40 This follows from the generic argument that retailers offer fundamentally intermediation activities in the same way that a business who transports shoes from A to B does not produce the shoes, but the bundle of transport services surrounding the shoes.
} 
added production function depends on the underlying form of the former. That literature suggests the conditions under which is can be done are that either that $\mathrm{Q}$ takes a special functional form so that the ratio of $\mathrm{Q}_{\mathrm{W}}$ to $\mathrm{Q}$ is fixed (either technologically, or that relative factor prices do not change) or that $\mathrm{Q}_{\mathrm{w}}$ is separable from the other inputs so that (3) can be written as:

$$
Q=F\left(A(D, M, X), Q_{W}\right)
$$

As Triplett and Bosworth (2004) point out, separability means that the elasticity of substitution between $\mathrm{D}, \mathrm{M}$ or $\mathrm{X}$ and $\mathrm{Q}_{\mathrm{W}}$ is zero, or that retailers choose $\mathrm{Q}_{\mathrm{W}}$ and then choose to allocate $\mathrm{M}$ and X independently of the choice of Qw. As Oi (2000) and Triplett and Bosworth (2004) point out, this is increasingly unlikely in retailing. For example, bikes used to be sold fully assembled, whereas now they are sold flat packed giving customers the choice to assemble the bikes themselves or have the shop do it. Thus there has been a change in $\mathrm{Q}_{\mathrm{w}}$ and this has necessitated a change in the ratio of $\mathrm{M}$ and $\mathrm{X}$ (in this case where $\mathrm{X}$ is the number of persons working at the store $)^{41}$. In sum, if separability does not hold, then TFP growth calculated from (4) will not give the same information as (3). This suggests that we should base our production function estimates on gross output and not margins.

A number of points are worth making. First, our assumption here that the distribution services, D are an input into final sales, Q follows other papers, see e.g. Ofer $(1973)^{42}$ and Triplett and Bosworth (2004). Ofer (1973, pp.367) posits a separable production function of the form $\mathrm{Q}=\mathrm{F}(\mathrm{A}, \mathrm{D}, \mathrm{M}, \mathrm{X})+\mathrm{Q}_{\mathrm{w}}$ on the assumption that consumers decide upon the ratio between sales and services produced (by choice of shop type). ${ }^{43}$ So the relation between final sales and bought in goods for resale is uninfluenced, he assumes, by input prices or technology. It has the interesting implication, also stressed by Betancourt (2004) and Oi (1992), that consumers are thus implicitly an input into the a retailer's output; if one of the elements of D for example is the full or self-service provided to a consumer, then the consumer's time is an input into retail production. This provides a framework to post the question of whether the shift from full to selfservice has affected retail productivity. ${ }^{44}$

Second, Betancourt (2004) assumes that both Q and D are joint outputs of a retailing firm, in which case the profit function is the appropriate estimation vehicle. By contrast, this framework assumes that $\mathrm{D}$ is an input into $\mathrm{Q}$. We make this because it is hard to imagine a consumer who could have $\mathrm{Q}$ without $\mathrm{D}$ or who could order $\mathrm{D}$ by itself without $\mathrm{Q}$. Consider Amazon.com where $\mathrm{Q}$ is the sales of books and $\mathrm{D}$ is the delivery and the website. Consumers cannot meaningfully order books without having them delivered, nor ask for the delivery alone. Consumers, like in retail stores, could of course "window" shop, but then there is no meaningful output (and this is likely a case where D is an input into future Q). One might however ask how we can argue that $\mathrm{D}$ is the appropriate output of retailers, but then argue that it is an input. The answer is that it is analogous to the distinction between output and value added in manufacturing. The output of a baker can be regarded as loaves of bread or value added in baking. However, value added in baking can also be regarded as an input into the gross output of loaves of bread (along with other inputs like flour) with the precise relation depending on

\footnotetext{
${ }^{41}$ So in the case of fully assembled bikes, $\mathrm{Q}_{\mathrm{W}}$ is the quantity of fully-assembled bikes and $\mathrm{X}$ is small. In the case of flat packed, $\mathrm{Q}_{\mathrm{W}}$ is less but $\mathrm{X}$ is larger if the store employs more workers to assemble the bikes.

42 “Sales may be looked upon as being produced from two inputs- goods purchased and services produced”, p.367. In turn Ofer regards services produced as being determined by factor inputs.

${ }^{43}$ So for example, to sell 20 pairs of shoes one has to buy in for final resale 20 pairs of shoes, a Leontief relation fixed over time, but consumers decide whether they want to buy the shoes in a full service, well decorated shop etc.

${ }^{44}$ It might for example have raises measured sales, but may not have raised D.
} 
separability conditions. Or value added in baking can, under some assumptions, be used to recover the output elasticities of various factors with respect to total output.

Finally, if competition is perfect and there are no economies of scale we would expect free entry to mean that real margins will just reflect the cost of distribution services provided (which in turn might consist of e.g. higher payments to staff). Thus the nominal value of $\mathrm{D}$, even though unpriced, would be recoverable from a manipulation of measurables. ${ }^{45}$ The real value of $\mathrm{D}$ however is more difficult, not least because deducing it from the real value of sales less the real value of bought-in goods for resale would require deducing a relatively small number from the subtraction of two very large numbers, both of which are likely measured with error (the real value of bought-in goods for example would have to reflect company-specific discounts). Thus in practice the compliers of National Accounts are unwilling to use the real value of margins as the output measure, even though using the real value of sales raises similar issues of measurement and lack of deflators.

Finally, a discussion and summary of results on retailing productivity using industry data is available on request.

\footnotetext{
${ }^{45}$ And this would in turn be determined by the level D that retailers provide. Such information, on for example, ambience, is hard to measure; Betancourt (2004) suggests using store-level consumer surveys.
} 